\title{
ARTICLE
}

\section{Forecasting the Impacts of Silver and Bighead Carp on the Lake Erie Food Web}

\author{
Hongyan Zhang* \\ Cooperative Institute for Limnology and Ecosystems Research, \\ School of Natural Resources and Environment, University of Michigan, \\ 4840 South State Road, Ann Arbor, Michigan 48108, USA
}

\section{Edward S. Rutherford and Doran M. Mason}

National Oceanic and Atmospheric Administration, Great Lakes Environmental Research Laboratory, 4840 South State Road, Ann Arbor, Michigan 48108, USA

\section{Jason T. Breck}

Department of Computer Sciences, University of Wisconsin-Madison, 1210 West Dayton Street, Madison, Wisconsin 53706, USA

\section{Marion E. Wittmann}

Department of Biological Sciences and Environmental Change Initiative, University of Notre Dame, Post Office Box 369, Notre Dame, Indiana 46656, USA; and Department of Biology, University of Nevada-Reno, 1664 North Virginia Street, Reno, Nevada 89557, USA

\section{Roger M. Cooke}

Resources for the Future, 1616 P Street Northwest, Washington, D.C. 20036, USA;

and Department of Mathematics, Delft University of Technology, Post Box, 2628 CN Delft,

The Netherlands; and University of Strathclyde, Glasgow City G1 1XQ, UK

\section{David M. Lodge}

Department of Biological Sciences and Environmental Change Initiative, University of Notre Dame, Post Office Box 369, Notre Dame, Indiana 46656, USA

\section{John D. Rothlisberger}

U.S. Forest Service, 626 East Wisconsin Avenue, Milwaukee, Wisconsin 53202, USA

\section{Xinhua Zhu}

Fisheries and Oceans Canada, 501 University Crescent, Winnipeg, Manitoba R3T 2N6, Canada

\section{Timothy B. Johnson}

Ontario Ministry of Natural Resources, Rural Route 4, 41 Hatchery Lane, Picton, Ontario KOK 2TO,

Canada

(C) Hongyan Zhang, Edward S. Rutherford, Doran M. Mason, Jason T. Breck, Marion E. Wittmann, Roger M. Cooke, David M. Lodge, John D. Rothlisberger, Xinhua Zhu, Timothy B. Johnson

*Corresponding author: zhanghy@umich.edu

This is an Open Access article. Non-commercial re-use, distribution, and reproduction in any medium, provided the original work is properly attributed, cited, and is not altered, transformed, or built upon in any way, is permitted. The moral rights of the named author(s) have been asserted.

Received December 6, 2014; accepted July 15, 2015 


\begin{abstract}
Nonindigenous bigheaded carps (Bighead Carp Hypophthalmichthys nobilis and Silver Carp H. molitrix; hereafter, "Asian carps" [AC]) threaten to invade and disrupt food webs and fisheries in the Laurentian Great Lakes through their high consumption of plankton. To quantify the potential effects of AC on the food web in Lake Erie, we developed an Ecopath with Ecosim (EwE) food web model and simulated four AC diet composition scenarios (high, low, and no detritus and low detritus with Walleye Sander vitreus and Yellow Perch Perca flavescens larvae) and two nutrient load scenarios (the 1999 baseline load and $2 \times$ the baseline [HP]). We quantified the uncertainty of the potential AC effects by coupling the EwE model with estimates of parameter uncertainty in AC production, consumption, and predator diets obtained using structured expert judgment. Our model projected mean $\pm \mathrm{SD} A C$ equilibrium biomass ranging from $52 \pm 34$ to $104 \pm 75 \mathrm{~kg} / \mathrm{ha}$ under the different scenarios. Relative to baseline simulations without AC, AC invasion under all detrital diet scenarios decreased the biomass of most fish and zooplankton groups. The effects of AC in the HP scenario were similar to those in the detrital diet scenarios except that the biomasses of most Walleye and Yellow Perch groups were greater under HP because these fishes were buffered from competition with $\mathrm{AC}$ by increased productivity at lower trophic levels. Asian carp predation on Walleye and Yellow Perch larvae caused biomass declines among all Walleye and Yellow Perch groups. Large food web impacts of AC occurred in only $2 \%$ of the simulations, where AC biomass exceeded $200 \mathrm{~kg} / \mathrm{ha}$, resulting in biomass declines of zooplankton and planktivorous fish near the levels observed in the Illinois River. Our findings suggest that AC would affect Lake Erie's food web by competing with other planktivorous fishes and by providing additional prey for piscivores. Our methods provide a novel approach for including uncertainty into forecasts of invasive species' impacts on aquatic food webs.
\end{abstract}

Invasive species are a major stressor on biodiversity, energy flow, and productivity in terrestrial and aquatic ecosystems. Currently, we lack an effective way to predict their impacts on food webs prior to establishment (Ricciardi et al. 2013). Such information and its associated uncertainty is instrumental for decision makers because not all nonindigenous species pose a threat. Knowledge of those species that may damage an ecosystem must be quantified to effectively allocate resources for prevention and control. Past efforts to forecast the ecological impacts of nonindigenous species in new environments have been based on the invasion history of target species (Ricciardi 2003; Kulhanek et al. 2011) or comparisons of the functional traits of the nonindigenous species with those of the native species residing in the recipient community (Kolar and Lodge 2002; Dick et al. 2013). Introduced species can also have impacts that vary across space and time, which can present substantial challenges to accurately forecasting the impacts of nonindigenous species in novel environments (Branch and Steffani 2004; Ricciardi and Kipp 2008). Furthermore, when combined with other stressors (e.g., excess nutrient loading), the impacts of nonindigenous species can lead to complex, profound, and long-term changes (or regime shifts) to the recipient ecosystems (Madenjian et al. 2013). To assess the potential ecosystem impacts of these synergistic and complex interactions, ecosystem models have increasingly been adopted to predict food web responses to the introduction of nonindigenous species (Pine et al. 2007; Langseth et al. 2012; Pinnegar et al. 2014).

In the Laurentian Great Lakes there are at least 184 established nonindigenous species (Ricciardi 2006), with many other species having a high potential to become established (Snyder et al. 2014). Two species of concern to the Great Lakes watershed include the Silver Carp Hypophthalmichthys molitrix and Bighead Carp H. nobilis (Kelly et al. 2011). Silver and Bighead carp, collectively known as bigheaded carps (henceforth referred to as "Asian carps" $[\mathrm{AC}])$, are filter feeders that consume phytoplankton, small zooplankton, detritus, and bacteria (Chen 1982; Sampson et al. 2009) and that have high rates of consumption, growth, and fecundity (DeGrandchamp et al. 2007). Asian carps have created unwanted impacts in systems where they have invaded (Cudmore et al. 2012). For example, in the Illinois River AC populations have increased exponentially (Chick and Pegg 2001) and have outcompeted native planktivores, leading to declines in native fishes (Schrank et al. 2003; Williamson and Garvey 2005; Sampson et al. 2009). Asian carps are currently established in watersheds adjacent to the Great Lakes. Furthermore, AC have been detected in the Great Lakes; three Bighead Carp have been collected in western Lake Erie since the 1990s (Morrison et al. 2004), and AC environmental DNA (eDNA) has been detected in tributaries to Lake Michigan as well as in Lake Erie (Jerde et al. 2011, 2013). Thus, the potential is very real for AC populations to become established in the Great Lakes and to impact food webs there.

Of all the Great Lakes, Lake Erie may be the most susceptible to AC. Lake Erie is at high risk owing to its connectivity to watersheds where AC occur (Kocovsky et al. 2012; Murphy and Jackson 2013), its high productivity (Cooke and Hill 2010; Cudmore et al. 2012), and the availability of suitable spawning habitats (Kocovsky et al. 2012) and adequate food (Anderson et al. 2015). Asian carps may directly disrupt the Lake Erie food web by competing with native planktivores and have a negative effect on fish recruitment by reducing prey for larval fishes. However, these negative effects may be 
countered by the potential of young $\mathrm{AC}$ to become an alternative prey for native predators (e.g., Walleye Sander vitreus, Yellow Perch Perca flavescens, and Smallmouth Bass Micropterus dolomieu). Food web models can capture the complexities of large aquatic ecosystems and track the direct and indirect response of the food web to perturbations to the system (e.g., a new invader). However, as model complexity increases, the ability to estimate model parameters and their uncertainty is reduced.

In this study, we combined a food web model, Ecopath with Ecosim (EwE) (Christensen and Walters 2004), with a novel approach to estimating parameter values with uncertainty called structured expert judgment (SEJ; Wittmann et al. 2015) to forecast with uncertainty the potential changes in the Lake Erie food web following the establishment of AC. We hypothesized that if AC were to become established in Lake Erie they would deplete the plankton in the water column and reduce the biomass of planktivores through competition for prey. We also hypothesized that the impacts of AC would differ depending on the productivity (nutrient loading) of the Lake Erie ecosystem and the availability of AC to piscivores. Specifically, we expected that higher nutrient loads would support higher biomass of $\mathrm{AC}$ and greater productivity of lower trophic levels, thus reducing the negative effects on native fishes. High availability of young $\mathrm{AC}$ to native piscivores would lower AC population growth and equilibrium biomass. In contrast, we hypothesized that if $\mathrm{AC}$ were to consume the larvae of other fishes, their impacts on fish recruitment would be greater.

\section{STUDY AREA}

Lake Erie is the smallest of the Laurentian Great Lakes by volume $\left(480 \mathrm{~km}^{3}\right)$ and the second smallest by surface area $\left(25,657 \mathrm{~km}^{2}\right)$; it is also the shallowest (mean depth $\left.=19 \mathrm{~m}\right)$ and most productive (spring average chlorophyll $a=11 \mu \mathrm{g} / \mathrm{L}$ ) (Figure 1; Bolsenga and Herdendorf 1993; Munawar et al. 2008) and has been affected by multiple anthropogenic stressors, including eutrophication, contaminants, wetland destruction, and invasive species introductions (Koonce et al. 1996; Ricciardi 2006; Dolan and Chapra 2012). Lake Erie contains three basins that differ in their physical and biological characteristics (the western, central, and eastern basins; Figure 1). In particular, Lake Erie's western basin is warmer and more productive and has more suitable spawning and nursery habitats for $\mathrm{AC}$ and native fishes than the central or eastern basins; thus, it has the highest potential for overlap between $\mathrm{AC}$ and native fishes. However, we chose to model the impacts of AC

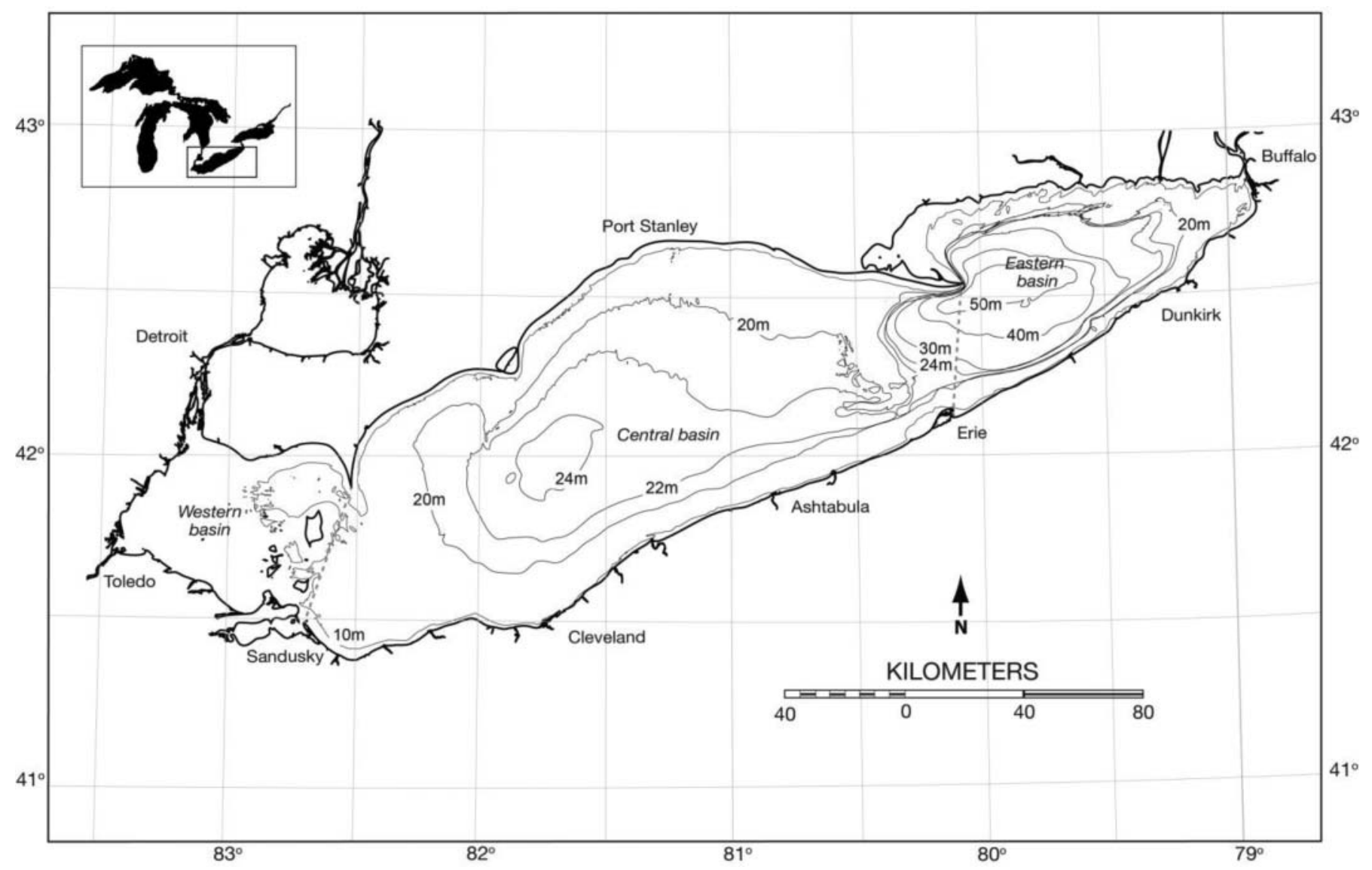

FIGURE 1. Map of Lake Erie showing its bathymetry and the delineation (by dotted lines) of the western, central, and eastern basins. 
on the food web of the lake as a whole instead of just the western basin for the following reasons. First, most of the prey fish species are found in all three basins, and many economically important species migrate among basins, including Walleyes (Wang et al. 2007) and Lake Whitefish Coregonus clupeaformis (Oldenburg et al. 2007). Second, AC are mobile fish and can travel an average of $7 \mathrm{~km} / \mathrm{d}$ (Bighead Carp) and $11 \mathrm{~km} / \mathrm{d}$ (Silver Carp), with a daily maximum of $64 \mathrm{~km}$ in rivers (DeGrandchamp et al. 2008). It is thus possible that they traverse multiple basins in Lake Erie. Finally, AC thrive in Lake Balaton, Hungary (Boros et al. 2014), a lake with a productivity comparable to that of the central basin of Lake Erie. Thus, the impacts of $\mathrm{AC}$ would be on a whole-lake scale.

\section{METHODS}

\section{Ecopath with Ecosim}

Ecopath with Ecosim (EwE) is a free ecosystem modeling software suite (http://www.ecopath.org/index.php) that is used to construct mass-balance trophic models of ecosystems (Christensen and Walters 2004). It has been used to study the effects of natural and anthropogenic stressors on ecosystems (Walters et al. 2008) and now is frequently used to study the effects of nutrient loading and invasive species on aquatic ecosystems (Blukacz-Richards and Koops 2012; Kao et al. 2014).

We selected EwE over other food web modeling approaches because it is a well-known and accepted tool that can capture the direct and indirect effects on the food web resulting from perturbations to the system (e.g., Kitchell et al. 2000). In addition, the effects of $A C$ are also likely modified by nutrient loading (Costa-Pierce 1992), and EwE has the ability to model various nutrient input scenarios. The EwE model is a popular choice given its moderate level of complexity, fast run time, and capacity to be linked to a generalized economic model of Lake Erie (J. Apriesnig and coworkers, Colorado State University, unpublished data). Details about Ecopath with Ecosim can be found in the user's manual as well as in many previous studies (e.g., Christensen and Walters 2004; Langseth et al. 2012; Kao et al. 2014). We also briefly describe the model in Supplement A.

\section{Base Ecopath Model for Lake Erie}

We used the standard version (6.3.909.0) of EwE for our modeling exercise. Our base Ecopath model of Lake Erie without AC consisted of 47 model groups including birds, fish, benthos, zooplankton, protozoa, bacteria, algae, and detritus (Table 1). We modeled four fish species (Walleye, Yellow Perch, Lake Trout Salvelinus namaycush, and Rainbow Trout Oncorhynchus mykiss) with more than one life stage. We modeled Walleyes and Yellow Perch over multiple life stages because they are important fishery species with well-documented life history data and the multistanza approach allowed simulations of larval fish predation scenarios (see below). We modeled Lake Trout and Rainbow Trout over only two stages because these two species are stocked and there is little evidence of natural reproduction. We estimated input values for biomass $(B)$, the ratio of production to biomass $(P / B)$, and the ratio of consumption to biomass $(Q / B)$ as well as diet composition from the published literature, field surveys, agency technical reports, and personal communications (Supplement B).

We balanced the Ecopath model using data from 1999 to 2001 (Supplement B) and then used Ecosim to simulate Lake Erie food web dynamics under forcing functions for nutrient loading, fish stocking, and fishery catches from 1999 to 2010 without AC (Figures A.3.1-A.3.3). We first used the time series fitting procedure in Ecosim to fit the model to the observed time series for 14 trophic groups. To further tune the model, we manually changed some of the coefficients of vulnerability of prey to predators until predicted biomasses matched the observed values and the error sums of squares were minimized. Vulnerability coefficients are the major parameters that are typically used to calibrate Ecosim models, as they define the transfer rates of prey between vulnerable and invulnerable components. High vulnerability coefficients indicate high prey availability. To further assess model performance, we compared the average biomass and coefficient of variation $(\mathrm{CV}=\mathrm{SD} /$ mean $)$ of each trophic group in simulated and observed time series.

\section{Structured Expert Judgment}

To determine the unknown parameter values of $\mathrm{AC}$ for EwE, we used structured expert judgment (SEJ) to quantify the uncertainties associated with the establishment of AC in Lake Erie (Wittmann et al. 2015). Structured expert judgment is a performance-based method of aggregating expert judgments (Cooke 1991) that has been used in a variety of applications (Goossens et al. 2008). Most recently, SEJ has been used in ecological settings to identify uncertainties with respect to biological invasions, including the effects of shipborne invasive species on ecosystem services (Rothlisberger et al. 2012) and the ecological effects and prevention of AC in the Great Lakes (Wittmann et al. 2014, 2015). Expert knowledge can be a valuable decision support tool in scenarios for which data are nonexistent, sparse, or debated (Aspinall 2010).

We used SEJ to estimate median values and uncertainty for the following key input variables for $\mathrm{AC}: P / B, Q / B$, and the fractional composition of $\mathrm{AC}$ in the diets of potential predators. Cooke et al. (2014) and Wittmann et al. (2015) provide detailed descriptions of SEJ theory and its application to uncertainty estimation for the impacts of AC on selected species in the Lake Erie food web. In brief, during an in-person elicitation interview (each expert was interviewed individually), fisheries experts $(n=11)$ estimated the 5th, 50th, and 95th percentiles of their subjective probability distributions for the above Ecopath parameters under a scenario of $\mathrm{AC}$ 
establishment in Lake Erie. The expert responses were then aggregated according to a performance-based methodology whereby each expert's performance was evaluated relative to a set of calibration variables, i.e., variables whose true values became known after the interviews (Cooke et al. 2014). This information was then used to weight each expert's response and aggregate all of the experts' responses to create a single subjective probability distribution for each AC input parameter in the Ecopath model.

\section{Adding AC to the EwE model}

Our base EwE model did not include $\mathrm{AC}$ and thus was named "noAC." To simulate the population increase of AC in the Lake Erie food web, we added AC after calibrating the base model. For each AC species (Silver Carp and Bighead Carp), we simulated scenarios with two age-groups: age 0 (up to 12 months) and yearling and older (age 1+; >12 months). We modeled age- 0 AC as a separate trophic group because these individuals are small enough to be vulnerable to predation by other food web members (thus allowing some degree of predator control on AC population growth), while age-1+ AC exceed most predators' gape size (Irons et al. 2011).

In Ecopath, we used Langseth et al.'s (2012) "method 2" to add AC. Briefly, this method sets the initial biomass of the invasive species at the beginning of the invasion to low values without creating an unbalanced food web (i.e., rebalancing Ecopath was not required) and controls the timing of population growth via an artificial source of mortality such as fishing. In our case, the initial biomass of age- $0 \mathrm{AC}\left(B_{Y}\right)$ was $0.4 \mathrm{~kg} / \mathrm{ha}$ for each species. The initial biomass of age- $1+\mathrm{AC}$ was determined by the multistanza procedure in Ecopath (Supplement A). This resulted in average initial biomasses of $3.3 \mathrm{~kg} / \mathrm{ha}$ for age-1+ Silver Carp and $2.7 \mathrm{~kg} / \mathrm{ha}$ for age-1+ Bighead Carp. The total initial biomass of all AC life stages represented approximately $5 \%$ of the total fish biomass. We also set an initial fishing mortality on age-1+ AC to be removed in Ecosim in model year 2014. The fractions of predator diets comprised of age-0 AC were selected from the subjective proportional distribution of diet fractions established by the SEJ (see Figure S.D.1 and the section "Implementation of Uncertainty in Model Simulations" below). To ensure that the Ecopath model remained balanced, we divided these diet fractions by 10. For example, if age-0 AC made up 5\% (by weight) of the total adult Walleye diet (determined by SEJ), we reduced this fraction by 10 -fold to $0.5 \%$ and rescaled the other prey contributions proportionately to make up the other $99.5 \%$ of the Walleye diet. The fractions of $\mathrm{AC}$ in the diets of predators increased proportionally with increases in AC biomass in the Ecosim simulations.

The values assigned to $Q / B$ and $P / B$ (or total mortality) for AC were also based on the SEJ results (Wittmann et al. 2015). A $Q / B$ value was assigned to age- $1+\mathrm{AC}$ from the SEJ distribution, and one for age-0 AC was determined by the Ecopath multistanza procedure. The $P / B$ was estimated for the entire $A C$ population from the SEJ, then partitioned into values for age-0 $\mathrm{AC}\left(P / B_{Y}\right)$ and age-1+ $\mathrm{AC}\left(P / B_{A}\right)$ (Appendix A.1; Figure S.D.1). We modified the AC diet composition from Chen's (1982) study, which reported that both species consumed detritus, bacteria, phytoplankton, and zooplankton, but in different quantities (Table 2).

In Ecosim, we assumed that the vulnerability of prey (PreyV) to AC was similar to the vulnerability of prey to Gizzard Shad Dorosoma cepedianum (PreyV $=11)$, a dominant planktivorous fish in Lake Erie with similar prey preferences and feeding mechanisms (Sampson et al. 2009). We also assumed a default value of 2 for the vulnerability of age-0 AC to their predators. From preliminary model simulations, we expected that the population growth and food web impacts of AC would vary depending on our assumptions for the vulnerability of prey to AC (PreyV) and the vulnerability of age-0 AC to predators (ACV). These values define the strength or control between trophic interactions in the diet matrix in Ecopath. Although a comprehensive sensitivity analysis of the model simulations (Bartell et al. 1986) to the variability in model input parameters was beyond the scope of this paper, we bounded the vulnerability parameter to determine the sensitivity of the results to parameter estimation. We varied PreyV from 1 to 2 (the default value), 11, and 20 while keeping ACV $=2$; we also varied ACV from 1 to 2 (the default value), 4, and 20 while keeping PreyV $=11$.

To simulate AC invasion in 2014, we forced the biomass of $\mathrm{AC}$ groups to be low using a time series of constant biomass of $0.01 \mathrm{~kg} / \mathrm{ha}$ from 1999 to 2013 and a fixed fishing mortality. In 2014, we removed fishing mortality and let AC populations grow. We set the maximum relative feeding time (Christensen et al. 2005) to 20 to maintain the density dependency assumption of the foraging arena (Ahrens et al. 2012). We did not change any other parameter value for other model groups in Ecopath before running the simulations in Ecosim.

\section{Simulation Scenarios}

Detrital diet.-Rather than just assuming a fixed diet of phytoplankton for Silver Carp and zooplankton for Bighead Carp (Cooke and Hill 2010), we also ran simulations to quantify the effect of differences in AC diets on the Lake Erie food web. Several studies have indicated that detritus is a substantial source of food for AC (Chen 1982; Costa-Pierce 1992; Duane Chapman, U.S. Geological Survey, personal communication), while other studies suggest that AC rely mainly on phytoplankton and zooplankton (Williamson and Garvey 2005; Sampson et al. 2009). An extensive literature review of Silver Carp feeding ecology suggests that AC are opportunistic feeders and consume whatever is available (Costa-Pierce 1992). The variability in AC diets suggests that they can easily adapt to new environments with different food resources (Calkins et al. 2012). To assess how the relative contribution of 
TABLE 1. Model groups in the EwE model and parameter values in the balanced Ecopath model without AC. Abbreviations are as follows: $B=$ biomass $(\mathrm{kg} / \mathrm{ha}), P / B=$ the yearly production-biomass ratio, $Q / B=$ the yearly consumption-biomass ratio, $\mathrm{EE}=$ ecotrophic efficiency, i.e., the fraction of production that is used in the system, and TL = trophic level. The balanced Ecopath model represents the Lake Erie food web during 1999.

\begin{tabular}{|c|c|c|c|c|c|c|}
\hline Group & Species & $B$ & $P / B$ & $Q / B$ & $\mathrm{EE}$ & $\mathrm{TL}$ \\
\hline DCCM & $\begin{array}{l}\text { Double-crested cormorant Phalacrocorax } \\
\text { auritus }\end{array}$ & 0.05 & 0.27 & 68.4 & 0.00 & 4.1 \\
\hline MERG & Red-breasted merganser Mergus serrator & 0.12 & 0.44 & 29.8 & 0.00 & 4.0 \\
\hline WAE_L & Walleye, larval & 0.01 & 5.07 & 23.4 & 0.84 & 3.2 \\
\hline WAE_Y & Walleye, age 0 & 0.04 & 2.62 & 9.9 & 0.84 & 4.4 \\
\hline WAE_J & Walleye, juvenile (age 1-2) & 0.94 & 0.38 & 3.7 & 0.85 & 4.3 \\
\hline WAE_A & Walleye, adult (age 3+) & 7.39 & 0.44 & 1.7 & 0.83 & 4.2 \\
\hline YEP_L & Yellow Perch, larval & 0.1 & 5.39 & 46.4 & 0.50 & 3.5 \\
\hline YEP_Y & Yellow Perch, age 0 & 0.37 & 2.67 & 19.7 & 0.26 & 3.4 \\
\hline YEP_J & Yellow Perch, juvenile (age 1) & 1.11 & 1.64 & 10.5 & 0.12 & 3.6 \\
\hline YEP_A & Yellow Perch, adult (age $2+$ ) & 6.09 & 0.68 & 4.7 & 0.49 & 3.8 \\
\hline GIZ & Gizzard Shad & 28.97 & 1.19 & 15.2 & 0.57 & 2.8 \\
\hline RBT_Y & Rainbow Trout, stocked yearlings & 0.01 & 0.001 & 7.3 & 0.00 & 1.0 \\
\hline RBT_A & Rainbow Trout, adult & 0.46 & 0.60 & 2.6 & 0.54 & 4.4 \\
\hline LWF & Lake Whitefish & 1.08 & 0.41 & 2.2 & 0.48 & 3.1 \\
\hline BBT & Burbot Lota lota & 0.16 & 0.26 & 1.5 & 0.88 & 4.4 \\
\hline WHP & White Perch Morone americana & 3.08 & 0.61 & 10.6 & 0.57 & 3.4 \\
\hline WHB & White Bass Morone chrysops & 3.07 & 0.62 & 5.2 & 0.77 & 4.0 \\
\hline SMB & Smallmouth Bass & 0.28 & 0.62 & 4.9 & 0.82 & 4.1 \\
\hline FWD & Freshwater Drum Aplodinotus grunniens & 11.27 & 0.68 & 4.3 & 0.91 & 3.2 \\
\hline ALW & Alewife Alosa pseudoharengus & 4.69 & 1.08 & 8.6 & 0.81 & 3.4 \\
\hline LKT_Y & Lake Trout, stocked yearlings & 0 & 0.001 & 12.9 & 0.00 & 1.0 \\
\hline LKT_A & Lake Trout, adult & 0.23 & 0.25 & 2.0 & 0.42 & 4.4 \\
\hline RBS & Rainbow Smelt Osmerus mordax & 19.22 & 1.54 & 7.5 & 0.95 & 3.4 \\
\hline CMP & Common Carp Cyprinus carpio & 1.15 & 0.28 & 4.8 & 0.40 & 2.3 \\
\hline RGB & Round Goby Neogobius melanostomus & 12.77 & 0.89 & 5.8 & 0.46 & 3.2 \\
\hline SUK & $\begin{array}{l}\text { White Sucker Catostomus commersonii, } \\
\text { Quillback Carpiodes cyprinus, and } \\
\text { Bigmouth Buffalo Ictiobus cyprinellus }\end{array}$ & 7.84 & 0.22 & 7.6 & 0.58 & 2.9 \\
\hline EMS & $\begin{array}{l}\text { Emerald Shiner Notropis atherinoides and } \\
\text { Spottail Shiner Notropis hudsonius }\end{array}$ & 11.53 & 1.39 & 13.2 & 0.93 & 3.5 \\
\hline CAT & $\begin{array}{l}\text { Channel Catfish Ictalurus punctatus and } \\
\text { Brown Bullhead Ameiurus nebulosus }\end{array}$ & 0.49 & 0.30 & 4.4 & 0.93 & 3.8 \\
\hline PanF & Panfish $^{\mathrm{a}}$ & 0.89 & 0.69 & 6.7 & 0.70 & 3.2 \\
\hline OthF & $\begin{array}{l}\text { Silver Chub Macrhybopsis storeriana, } \\
\text { Trout-perch Percopsis omiscomaycus, and } \\
\text { Common Logperch Percina caprodes }\end{array}$ & 3.77 & 0.92 & 16.0 & 0.88 & 3.3 \\
\hline DREI & Zebra mussel and quagga mussel & 3181 & 1.39 & 6.4 & 0.01 & 2.1 \\
\hline AMPH & Amphipoda and Isopoda & 7.97 & 4.29 & 22.7 & 0.78 & 2.0 \\
\hline CHIR & Chironomidae & 67.86 & 2.66 & 12.7 & 0.89 & 2.0 \\
\hline OLIG & Oligochaeta & 51.3 & 4.60 & 30.7 & 0.11 & 2.0 \\
\hline MOLL & Ephemeroptera & 7.51 & 2.55 & 12.1 & 0.86 & 2.1 \\
\hline EPHE & Gastropoda, Sphaeriidae, and Bivalvia & 4.08 & 5.03 & 32.5 & 0.72 & 2.0 \\
\hline OthB & Other benthos (mainly insect larvae) & 14.7 & 4.85 & 28.9 & 0.61 & 2.2 \\
\hline CLAD & Herbivorous cladocerans & 41.3 & 56.3 & 208.5 & 0.23 & 2.4 \\
\hline COPE & Calanoida and Cyclopoida & 34.9 & 13.3 & 51.2 & 0.49 & 2.4 \\
\hline
\end{tabular}


TABLE 1. Continued.

\begin{tabular}{llrrrrr}
\hline Group & \multicolumn{1}{c}{ Species } & $B$ & $P / B$ & $Q / B$ & EE & TL \\
\hline ROTI & Rotifera & 16.41 & 49.1 & 204.6 & 0.38 & 2.6 \\
PRED & Leptodora kindtii, and spiny water flea & 2.58 & 26.2 & 97.0 & 0.74 & 3.4 \\
& $\quad$ Bythotrephes longimanus & & & & & \\
& Ciliates and heterotrophic flagellates & 28.57 & 138.6 & 462.0 & 0.80 & 2.1 \\
PROT & Bacteria & 38.27 & 212.4 & 382.4 & 0.82 & 2.0 \\
BACT & Picoplankton & 20.71 & 343.8 & & 0.63 & 1.0 \\
PICO & Edible algae & 115.4 & 167.5 & & 0.91 & 1.0 \\
EDIB & Cyanophyta & 67.3 & 343.8 & & 0.22 & 1.0 \\
CYAN & Suspended and sediment detritus & 1,766 & & & 0.44 & 1.0 \\
DETR & & & & & & \\
\hline
\end{tabular}

${ }^{a}$ Rock Bass, Bluegill, Pumpkinseed, White Crappie, and Black Crappie.

${ }^{b}$ Mainly Chlorophyta, Cryptophyta, and Bacillanophyta.

detritus to AC diets affects the food web, we ran simulations using three AC diet detritus levels: high (AC_HD), using Chen's (1982) level derived from AC diet studies in Lake Donghu; low (AC_LD), using one-half of the AC_HD level; and none (AC_ND). We assumed that the detritus levels in Lake Erie were lower than those in Lake Donghu based on the reported values of total phosphorus and particulate organic carbon (Liu et al. 2000; Havens et al. 2001; Smith et al. 2005; Upsdell 2005). In addition, Lake Donghu is much shallower (mean depth $=2.8 \mathrm{~m}$ ) than Lake Erie, so that sediment resuspension is likely to be much more common in Lake Donghu than in Lake Erie. Suspended detritus is more available to AC than that on the bottom. As we decreased the fraction of detritus in the diet, we reapportioned it to algae for Silver Carp and to zooplankton for Bighead Carp. In the scenarios involving fish larvae in AC diets, we used the AC_LD model and modified the AC diet composition to include fish larvae.

Feeding on larval fish.-We have found no evidence in the published literature that $\mathrm{AC}$ consume larval fish or fish eggs. However, several management biologists and SEJ experts in

TABLE 2. Diet composition (\% the total diet on a wet-weight basis) of AC in our EwE model for the low-detritus scenario with AC diet (AC_LD), modified from Chen (1982, Table A.2.1). We assumed that young and age-1+ Silver Carp had the same diet composition and similarly for young and age-1+ Bighead Carp. See Table 1 for full species group names.

\begin{tabular}{lcc}
\hline Prey group & Silver Carp & Bighead Carp \\
\hline CLAD & 6.2 & 37.2 \\
COPE & 4.0 & 16.0 \\
ROTI & 0.6 & 0.4 \\
PRED & 1.0 & 2.0 \\
PROT & 0.4 & 0.2 \\
BACT & 21.1 & 12.0 \\
PICO & 5.2 & 5.0 \\
EDIB & 31.9 & 6.2 \\
CYAN & 10.1 & 7.8 \\
DETR & 19.5 & 13.3 \\
\hline
\end{tabular}

the Great Lakes have suggested that AC probably feed on fish larvae given how flexible they are in their diet composition (Wittmann et al. 2015) and the occurrence of AC adults on Walleye and Yellow Perch spawning grounds when larvae of those species are present (Cudmore et al. 2012; Kocovsky et al. 2012; Wang et al. 2012). To test the hypothesized effect of predation on Walleye and Yellow Perch larvae by AC, we assumed that $\mathrm{AC}$ had equal preferences for percid larvae and cladocerans in order to calculate the fraction of larval percids in the $\mathrm{AC}$ diet. That is, the ratio of the fraction of percid larvae in the $\mathrm{AC}$ diet to that of cladocerans was set equal to the ratio of the biomass of percid larvae in the environment to that of cladocerans. Since the biomass of percid larvae was much lower than that of cladocerans, the resulting diet fraction of percid larvae was very low. We averaged the diet fraction over 12 months, as Ecosim runs on a time step of 1 month. We then adjusted the total diet fraction to 1 using the procedure described above for adding AC to AC predators' diet. This scenario was referred to as AC_LF.

Nutrient loading.-We ran the above simulations under the observed 1999 nutrient load (baseline) conditions. However, given the likelihood of increased nutrient loads under conditions of changing climate and land use (Michalak et al. 2013), we also ran simulation scenarios under the nutrient loads observed in 2007, which were twice as high as the 1999 levels (Dolan and Chapra 2012). This scenario is referred to as AC_HP. In addition, to assess the net impacts of AC on the food web under high phosphorus loading conditions, we also ran the noAC model with high phosphorus loads (twice the baseline loads), a scenario referred to as noAC_HP.

\section{Implementation of Uncertainty in Model Simulations}

We used an inverse transform sampling procedure (Figure S.D.2) to sample from the distribution of potential parameter values (as determined by SEJ) for the model runs. This procedure randomly and independently selected values from the subjective probability distributions for the AC parameters $P / B, Q / B$, and the fraction of $\mathrm{AC}$ in predator diets. After 
TABLE 3. Diets (\% of the total diet on a wet-weight basis) of piscivorous birds and fish (columns) in the balanced Ecopath model without AC. See Table 1 for full species group names.

\begin{tabular}{|c|c|c|c|c|c|c|c|c|}
\hline Prey/predator & DCCM & MERG & WAE_Y & WAE_J & WAE_A & RBT_A & BBT & LKT_A \\
\hline WAE_L & & & & 0.08 & 0.08 & & & \\
\hline WAE_Y & 0.4 & 0.99 & & 0.17 & 0.29 & & & \\
\hline WAE_J & 0.24 & & & 0.15 & 0.1 & & & \\
\hline WAE_A & & 1.49 & & & & & & \\
\hline YEP_L & & & & 0.1 & 0.1 & & & \\
\hline YEP_Y & 0.35 & 0.4 & 3.83 & 0.1 & 0.15 & 6.62 & 2.06 & 0.36 \\
\hline YEP_J & 1.62 & 1.82 & & 0.41 & 0.5 & & & \\
\hline YEP_A & 0.39 & 1.83 & & 0.27 & 0.34 & & & \\
\hline GIZ & 39.67 & 50.43 & 27.23 & 22.52 & 29.97 & 0.05 & 1 & 9.82 \\
\hline LWF & & & & & & & & 0.02 \\
\hline BBT & 0.1 & & & & & & & 0.3 \\
\hline WHP & 0.21 & 8.77 & 24.8 & 0.11 & 1.95 & 9.38 & 2.92 & \\
\hline WHB & 3.21 & & 18.81 & 3.16 & 1.57 & 0.02 & 2 & \\
\hline SMB & 0.15 & & & & & & & 0.24 \\
\hline FWD & 26.79 & 7.21 & 1.71 & 0.03 & & 2.84 & & 0.18 \\
\hline ALW & 2.69 & 0.14 & 10.22 & 15.42 & 14.98 & 1.72 & 1.89 & 1.48 \\
\hline RBS & 1.5 & 4.38 & 7.44 & 31.97 & 30.83 & 33.01 & 61.17 & 65.32 \\
\hline CMP & 0.32 & 0.49 & & & & & & \\
\hline RGB & 7.44 & 3.18 & & 6.11 & 6.86 & 0.7 & 14.07 & 13.84 \\
\hline SUK & 0.15 & 0.58 & & & 4.86 & & & \\
\hline EMS & 7.51 & 7.11 & 4.2 & 7.63 & 3.04 & 42.44 & 10.71 & 8.14 \\
\hline CAT & 1.22 & 0.49 & & & & & & \\
\hline PanF & 1.92 & 0.97 & 0.76 & 0.41 & 0.95 & & & \\
\hline OthF & 0.12 & & & 6.37 & 0.43 & 2.59 & 3.1 & 0.21 \\
\hline DREI & & 0.05 & & & & & 0.89 & \\
\hline OthB & & 5.68 & & & & & & \\
\hline PRED & & & & & & 0.15 & & \\
\hline
\end{tabular}

partitioning $P / B$ into predation mortality, fishing mortality, and other mortality and scaling down the fraction of $\mathrm{AC}$ in predator diets, we updated these values in the Ecopath model with AC. Next, we checked the balance of the food web in Ecopath (to ensure that ecotrophic efficiency $\leq 1$ and consumption $>$ growth and wastes for all model groups), and if the food web balanced we used Ecosim to simulate the ecosystem response to $\mathrm{AC}$ invasion under that value set. If the model did not balance, we discarded the selected input value set and selected another random set of values. This process was repeated 100 times (Figure S.D.1). When the Ecopath model was successfully balanced, we ran Ecosim and obtained the simulated AC biomass over a 120-year period after the introduction of AC (a total of 134 years). We ran the simulations for this long to ensure that the biomass of trophic groups reached equilibrium (the trophic response usually reached equilibrium about 20 years after introduction in 2014). We then averaged the changes in the simulated biomass of model groups over the last 10 years of the simulation (i.e., years 125-134) and retained the range of model output for each group.
To determine the changes in the food web, for each model run we calculated the difference in the biomass of each trophic group $i$ between the AC simulations and baseline conditions $\left(B_{i, \mathrm{AC}}-B_{i, \mathrm{noAC}}\right)$ as well as the percent difference

$$
\frac{B_{i, \mathrm{AC}}-B_{i, \mathrm{noAC}}}{B_{i, \mathrm{noAC}}} \times 100 .
$$

Similarly, for the scenario with high phosphorus loading we calculated the difference in the biomass of each trophic group between the AC_HP simulation and the simulation with no $\mathrm{AC}$ and high phosphorus loading $\left(\mathrm{B}_{i, \mathrm{AC} \_\mathrm{HP}}-\mathrm{B}_{i, n o \mathrm{AC} \_\mathrm{HP}}\right)$ as well as the percent difference

$$
\frac{B_{i, \mathrm{AC} \_ \text {HP }}-B_{i, \text { noAC_HP }}}{B_{i, \text { noAC_} \_ \text {HP }}} \times 100 .
$$

We report the mean \pm SD of absolute biomass (Table S.C.1; Figures S.D.3-S.D.6) and the percent changes in biomass over all Ecosim runs for each scenario. Following Kitchell et al. (2000), we 
considered a $>25 \%$ change in a state variable (i.e., equilibrium biomass with no $\mathrm{AC}$ ) in response to a manipulation (i.e., AC introduction) to indicate an ecologically significant change in the food web. If the response was $<25 \%$, we considered it ecologically insignificant or within the range of error of the empirical data used to estimate the model parameters.

Due to the large number of simulation runs $(n=428)$, it is impractical to summarize the changes in trophic interactions after AC introduction for all food web members for each scenario. For selected trophic groups, we report the consumption rate and fractional composition of the top five prey groups in predator diets from a single run of each scenario, along with predation mortality on prey before and after the introduction of AC.

\section{RESULTS}

\section{Balanced Ecopath Model and Ecosim Calibration without AC}

The biomass, production, consumption, ecotrophic efficiency, and trophic level of all food web components in the balanced Lake Erie Ecopath model are shown in Table 1.
Gizzard Shad has the highest fish biomass $(28.97 \mathrm{~kg} / \mathrm{ha})$, followed by Rainbow Smelt, Round Goby, shiners (Cyprinidae), and Freshwater Drum. The adult population biomasses of Walleyes and Yellow Perch were 7.39 and $6.09 \mathrm{~kg} / \mathrm{ha}$, respectively, while those of White Perch and White Bass were both $3.1 \mathrm{~kg} / \mathrm{ha}$. The biomass of waterbirds was relatively low $(0.05-0.12 \mathrm{~kg} / \mathrm{ha})$. The remaining nearshore and coldwater species had much lower biomass $(<0.5 \mathrm{~kg} / \mathrm{ha})$. Waterbirds, Walleyes, Burbot, White Bass, Smallmouth Bass, and Lake Trout were among the top predators in the Lake Erie food web, with trophic levels above 4.0; these predators fed primarily on other fish groups (Tables 3, 4), while other fish groups had trophic levels between 3 and 4 (Table 1). Gizzard Shad, suckers (Catastomidae), and Common Carp consumed a relatively large amount of detritus or benthos (Tables 4,5). Benthos and zooplankton mainly fed on detritus and phytoplankton and were characterized by trophic levels between 2 and 3. Predatory cladocerans, which consumed other zooplankton, had a higher trophic level of 3.4 (Tables 1, 6).

The Ecosim model projections agreed with the observed biomass dynamics for most groups, having similar means and coefficients of variation (Figure 2, Table 7; error sum of

TABLE 4. Diets (\% of the total diet on a wet-weight basis) of omnivorous fish (columns) in the balanced Ecopath model without AC. See Table 1 for full species group names.

\begin{tabular}{lcccccccc}
\hline Prey/predator & YEP_J & YEP_A & WHP & WHB & SMB & FWD & RGB & CAT \\
\hline WAE_L & & 0.08 & 0.02 & 0.02 & 0.04 & & & \\
YEP_L & & & 0.58 & 0.1 & 2.15 & & & \\
YEP_Y & 0.07 & 0.07 & & 0.43 & 0.53 & & & \\
GIZ & 5.78 & 4.67 & 3.96 & 19.56 & 18.48 & 5.38 & & \\
WHP & & & & & 7.98 & & & \\
WHB & & & 0.99 & & 6.19 & & & \\
SMB & & & & & 0.6 & & & \\
FWD & 0.21 & 0.17 & 0.61 & 1.06 & 1.04 & & & \\
ALW & 14.7 & 25.19 & 7.44 & 39.21 & 3.24 & 2.37 & & \\
RBS & 5.68 & 4.94 & & & 37.25 & & 0.18 & \\
RGB & 8.62 & 16.77 & 6.45 & 8.93 & 3.09 & 2.43 & & \\
EMS & & 0.18 & & & 1.43 & & & 6.97 \\
PanF & & & & 1.17 & 3.91 & & & \\
OthF & 3.85 & 2.33 & 0.56 & & & 35.72 & 46.58 & 9.57 \\
DREI & 3.62 & 0.69 & 10.61 & 3.77 & & 9.68 & 0.02 & 1.8 \\
AMPH & 22.14 & 18.35 & 20.11 & 1.91 & & 28.63 & 5.3 & 12.85 \\
CHIR & 9.8 & 8.42 & 9.91 & & & 2.4 & & \\
OLIG & 1.9 & 4.13 & & & & 0.27 & 7.95 & 1.82 \\
MOLL & 2.24 & 1.81 & & 7.94 & & 0.62 & 3.15 & 8.02 \\
EPHE & 1.05 & 0.87 & 4.96 & 3.97 & 8.94 & 4.41 & 1.97 & 13.07 \\
OthB & 12.46 & 8.37 & 26.55 & 8.92 & 0.88 & 5.84 & 25.8 & 7.92 \\
CLAD & & & 0.3 & 0.99 & & & &
\end{tabular}


TABLE 5. Diets (\% of the total diet on a wet-weight basis) of planktivorous and benthivorous fish (columns) in the balanced Ecopath model without AC. See Table 1 for full species group names.

\begin{tabular}{|c|c|c|c|c|c|c|c|c|c|c|c|c|}
\hline Prey/predator & WAE_L & YEP_L & YEP_Y & GIZ & LWF & ALW & RBS & CMP & SUK & EMS & PanF & OthF \\
\hline YEP_L & & & & & & & & & & & 0.43 & \\
\hline \multicolumn{13}{|l|}{ GIZ } \\
\hline RBS & & & & & & & 0.1 & & & & & \\
\hline RGB & & & & & & & & & 1.53 & & & \\
\hline EMS & & & & & & & 1.68 & & & & & \\
\hline PanF & & & & & & & & & & & 0.03 & \\
\hline OthF & & & & & 1.60 & & 1.7 & & & & & \\
\hline DREI & & & 0.02 & & 8.15 & & & 3.00 & & & & \\
\hline AMPH & & & 4.50 & 0.01 & 20.89 & 1.45 & & 9.65 & & & 24.98 & 2.7 \\
\hline CHIR & 40.00 & & 7.47 & 0.10 & 51.08 & & 33 & 4.50 & 39.46 & 15 & 21.75 & 10 \\
\hline OLIG & & & 4.50 & & & & & & 15.00 & 3 & & 8 \\
\hline MOLL & & & 0.36 & & 7.60 & & & 2.00 & 2.41 & & 9.79 & 0.5 \\
\hline EPHE & 1.00 & & & & & & & 0.03 & 1.66 & & 4.34 & \\
\hline OthB & 40.00 & 1.67 & 1.39 & 1.37 & 3.59 & 10.61 & & 5.30 & 0.90 & 0.26 & 17.47 & 10.80 \\
\hline CLAD & 19.00 & 59.02 & 49.08 & 29.41 & 7.10 & 30.62 & 25.6 & 0.25 & 5.46 & 39.8 & 15.15 & 45.00 \\
\hline COPE & & 21.28 & 17.69 & 10.90 & & 54.33 & 25.8 & 0.33 & 12.31 & 21.9 & 5.05 & 20.00 \\
\hline ROTI & & 12.02 & 10.00 & 10.00 & & & & & & 5.00 & & 2.00 \\
\hline PRED & & 6.01 & 5.00 & 1.00 & & 3.00 & 12.1 & & & 15 & 1.01 & 1.00 \\
\hline PROT & & & & 5.00 & & & & & 2.00 & & & \\
\hline \multicolumn{13}{|l|}{ BACT } \\
\hline PICO & & & & & & & & & & & & \\
\hline EDIB & & & & 14.2 & & & & 19.65 & 5.99 & & & \\
\hline CYAN & & & & & & & & 10.00 & & & & \\
\hline DETR & & & & 28.03 & & & & 45.29 & 13.30 & & & \\
\hline
\end{tabular}

squares $=61.24, n=142$ ), although the seasonal dynamics most evident at lower trophic levels could only be compared with averages provided by empirical observation over growing seasons. For other groups, the model predicted similar trends over time, with similar variation around the mean (observed data: $\mathrm{CV}$ range $=0.35-0.76$; simulated data: $\mathrm{CV}$ range $=$ 0.12-0.76; Table 7).

\section{Model Sensitivity to Vulnerability Parameters}

The biomass of all four AC model groups was more sensitive to the vulnerability of prey to $\mathrm{AC}$ (PreyV) than to the vulnerability of age-0 AC to AC predators (ACV) (Figure 3). For example, the biomass of age-1+ Silver Carp ranged from 7.4 to $81.7 \mathrm{~kg} / \mathrm{ha}$ when PreyV was varied $(\mathrm{ACV}=2)$ but only from 47.4 to $48.1 \mathrm{~kg} / \mathrm{ha}$ when ACV (PreyV = 11) was varied. Moreover, selected food web groups showed larger biomass changes with changes in PreyV (Figure 4) than with changes in ACV (Figures A.3.4, S.D.7).

\section{Uncertainty Analyses using SEJ}

The numbers of successfully balanced Ecopath models were similar among simulation scenarios. Depending on the scenario, from $81 \%$ to $88 \%$ of the Ecopath model iterations achieved mass balance and were used in Ecosim simulations (Table A.2.2,). The causes of unbalanced Ecopath models included high predation mortality on age- $0 \mathrm{AC}$ (the predominant cause), zero consumption by age- $1+\mathrm{AC}$, negative $\mathrm{AC}$ respiration (consumption was less than production), high predation on zooplankton groups, and high predation mortality by AC on larval Walleyes (Table A.2.3).

\section{AC Biomass}

Our model showed that it took about two decades for AC to establish a stable population in Lake Erie after invasion (Figure 5). The mean $\pm \mathrm{SD}$ total $\mathrm{AC}$ biomass at the end of the 120-year simulation ranged from $52.4 \pm 33.6$ to $104.3 \pm$ $74.9 \mathrm{~kg} / \mathrm{ha}$ across all scenarios (Figure 5; Table A.2.3). The scenarios with no detritus produced the lowest mean AC biomass, while those with high phosphorus loads produced the highest. The biomass of age-0 Silver Carp ranged from $1.6 \pm$ 0.2 to $2.3 \pm 0.3 \mathrm{~kg} / \mathrm{ha}$, and that of age-0 Bighead Carp was similar (1.4 \pm 0.2 to $2.4 \pm 0.3 \mathrm{~kg} / \mathrm{ha})$. The biomass of age- $1+$ Silver Carp ranged from $27.4 \pm 26.4$ to $51.5 \pm 65.0 \mathrm{~kg} / \mathrm{ha}$, and that of age-1+ Bighead Carp ranged from $21.9 \pm 23.0$ to $48.2 \pm 42.3 \mathrm{~kg} / \mathrm{ha}$ (Table A.2.3). The maximum total AC biomass for all scenarios at the end of the simulations was 

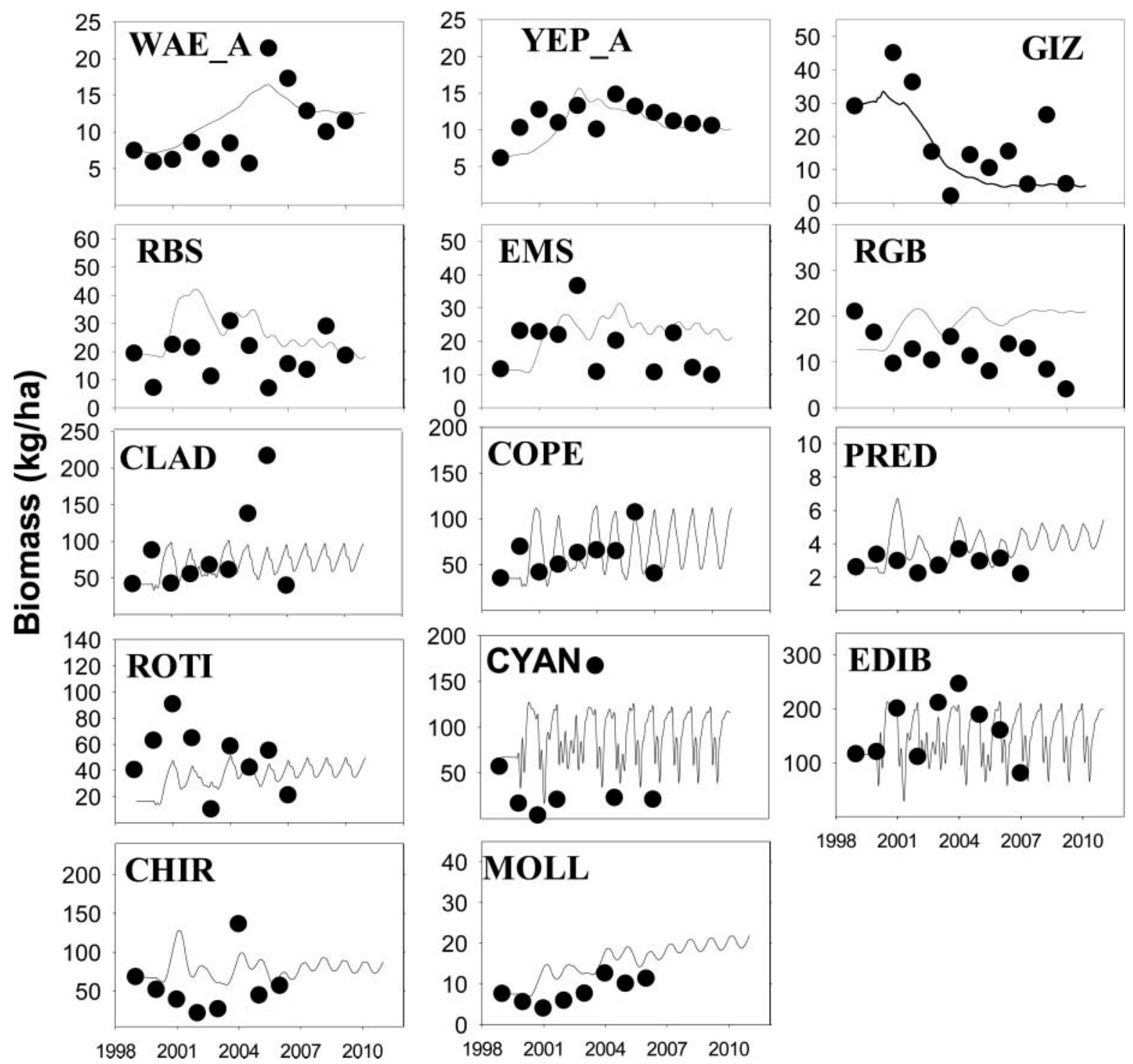

FIGURE 2. Model calibration of selected species/groups in the Lake Erie EwE model. The lines represent model-simulated biomass values, and the circles are empirical observations from resource agency monitoring surveys. There were 12 years of observed biomass data for fish species (1999-2010), 9 years for plankton groups (1999-2007), and 8 years for benthic groups (1999-2006). See Table 1 for full species/group names.

$394.2 \mathrm{~kg} / \mathrm{ha}$. At the end of the simulations, AC biomass ranged from $29 \%$ to $34 \%$ of total fish biomass (Table A.2.3).

\section{Food Web Responses to AC Introduction}

Detrital diet scenarios. - The food web responses to the introduction of AC were similar across scenarios with different levels of detritus in the $\mathrm{AC}$ diet. The biomass of most planktivore and piscivore groups tended to decrease relative to the baseline scenario (Figure 6; Table S.C.2). Under the three detrital scenarios, adult Walleye biomass decreased by $8.7 \pm$ $13.2 \%$ to $12.3 \pm 11.2 \%$, adult Rainbow Trout biomass by 13.3 $\pm 12.0 \%$ to $15.3 \pm 13.1 \%$, Gizzard Shad biomass by $24.3 \pm$
$9.0 \%$ to $26.5 \pm 10.4 \%$, and shiner biomass by $32.3 \pm 17.3$ to $36.6 \pm 15.6 \%$. Walleye consumption of prey was lower than in the baseline simulation without AC (Figure 7). Although Walleye consumption of age- 0 AC constituted as much as $18 \%$ of their diet, the age- 0 AC did not compensate for the loss of other prey fish in Walleye diets. Several fish species increased in biomass in response to the $\mathrm{AC}$ invasion. For example, the biomass of Smallmouth Bass increased by 13.2 $\pm 17.0 \%$ to $16.0 \pm 16.7 \%$ and that of adult Yellow Perch by $<5 \pm 15 \%$. The increase in the biomass of Smallmouth Bass was attributable to increased consumption, with age- 0 AC contributing about $18 \%$ of their diet (Figure 7). The consumption of prey by Gizzard Shad and shiners decreased by averages of 
TABLE 6. Diets (\% of the total diet on a wet-weight basis) of benthos and plankton (columns) in the balanced Ecopath model without AC. See Table 1 for full species group names.

\begin{tabular}{|c|c|c|c|c|c|c|c|c|c|c|c|c|c|}
\hline Prey/predator & DREI & AMPH & CHIR & OLIG & MOLL & EPHE & OthB & CLAD & COPE & ROTI & PRED & PROT & BACT \\
\hline AMPH & & 3.07 & & & & & & & & & & & \\
\hline CHIR & & 0.67 & 1.42 & & & & & & & & & & \\
\hline CLAD & & & & & & & 2.60 & & 0.50 & & 82.40 & & \\
\hline COPE & & & & & & & 7.85 & & 0.50 & & 6.00 & & \\
\hline ROTI & 1.00 & & & & & & 0.31 & & 1.00 & & 11.60 & & \\
\hline PROT & 4.52 & & & & & & & 16.43 & 25.00 & 10.02 & & & \\
\hline BACT & 6.62 & & & & 10.00 & & & 19.99 & 10.00 & 45.79 & & 14.08 & \\
\hline PICO & 5.80 & & & & 10.00 & & & 10.00 & 10.00 & 18.34 & & 12.34 & \\
\hline EDIB & 22.74 & 19.79 & 20.76 & 20.00 & 14.00 & 24.12 & 26.61 & 53.58 & 53.00 & 25.86 & & 43.49 & \\
\hline CYAN & 4.84 & 5.00 & 9.70 & 1.00 & 1.00 & 4.00 & 7.63 & & & & & 30.09 & \\
\hline DETR & 54.48 & 71.5 & 68.10 & 79.00 & 65.00 & 71.88 & 55.00 & & & & & & 100 \\
\hline
\end{tabular}

$15 \%$ and $41 \%$, respectively, under the detrital diet scenarios, but the predation mortality on these two groups was slightly lower than in the baseline (Figure 8).

The biomass of omnivorous fish showed a variable response to the simulated AC invasion (Figure 6; Table S. C.2). Species that feed more on pelagic prey decreased in biomass, while species that feed more on benthic prey either increased or showed no change in biomass. For example, in the AC_LD scenario the biomass of White Perch decreased by an average of $45.9 \pm 39.4 \%$ while that of Lake Whitefish increased by an average of $6.9 \pm 5.1 \%$. White Perch consumption decreased by $40-54 \%$ under the detrital scenarios (Figure 8). The biomass of benthivorous Round Goby decreased slightly (by $5.2 \pm 2.9 \%$ ) due to increased predation by Smallmouth Bass.

TABLE 7. Mean values (coefficients of variation in parentheses) of observed data and EwE-simulated time series data. See Table 1 for full species group names.

\begin{tabular}{lcr}
\hline Model group & Observation & Simulation \\
\hline WAE_A & $1.01(0.49)$ & $1.22(0.29)$ \\
YEP_A & $1.13(0.19)$ & $1.10(0.26)$ \\
CLAD & $8.29(0.71)$ & $7.51(0.28)$ \\
COPE & $5.93(0.37)$ & $7.98(0.46)$ \\
PRED & $0.29(0.17)$ & $0.41(0.28)$ \\
ROTI & $4.94(0.49)$ & $4.35(0.34)$ \\
EDIB & $15.89(0.35)$ & $16.12(0.31)$ \\
CYAN & $10.45(1.25)$ & $8.87(0.30)$ \\
GIZ & $2.17(0.76)$ & $1.32(0.76)$ \\
RBS & $1.81(0.41)$ & $2.73(0.32)$ \\
EMS & $2.33(0.63)$ & $2.57(0.27)$ \\
RGB & $1.16(0.39)$ & $1.64(0.12)$ \\
CHIR & $5.52(0.65)$ & $7.34(0.20)$ \\
MOLL & $0.80(0.38)$ & $1.57(0.29)$ \\
\hline
\end{tabular}

Although the biomass of most benthic invertebrate groups increased slightly, that of the mollusk and dreissenid groups decreased in response to the AC invasion (Figure 6; Table S. C.2). In general, the percentage changes were very small. Zooplankton showed large decreases in biomass, while phytoplankton showed minimal changes. For example, under the AC_LD scenario the biomass of herbivorous cladocerans, copepods, and predaceous cladocerans decreased by $14.4 \pm$ $9.1 \%, 14.2 \pm 8.5 \%$, and $24.2 \pm 14.9 \%$, respectively. Under the varying detrital scenarios, the zooplankton groups decreased their consumption and experienced increases in predation (Figure 9). The changes in predation mortality were larger than the changes in consumption. For example, the predation rates on predaceous cladocerans increased by $22-24 \%$, while their consumption decreased by $12-19 \%$ compared with baseline conditions without AC. The consumption of herbivorous cladocerans decreased by 6-10\%, while their predation mortality increased by $19-59 \%$.

Larval predation scenarios.-High AC predation rates on percid larvae (mostly Walleye larvae) frequently caused mass imbalances in the Ecopath model (Table A.2.3). Walleye larvae had a high baseline ecotrophic efficiency $(0.84$; Table 1 [ecotrophic efficiency refers to the fraction of the production that is used in the system]), and greater AC predation on Walleye larvae often increased the ecotrophic efficiency of Walleye larvae to $>1.0$, thus violating the mass balance of the model. Six of the 19 imbalanced Ecopath situations were due to the invalid ecotrophic efficiency of Walleye larvae in the scenarios with larval fish predation by AC. Compared with the baseline scenario of no AC, predation on larval fish decreased the biomass of all Walleye and Yellow Perch groups (Figure 6). The biomass of larval Walleyes decreased by an average of $9.0 \pm 7.6 \%$ and that of larval Yellow Perch by $29.1 \pm 28.4 \%$ (Figure 6). Other food web groups responded to the AC_LF scenario much as they did to the detrital scenarios. 


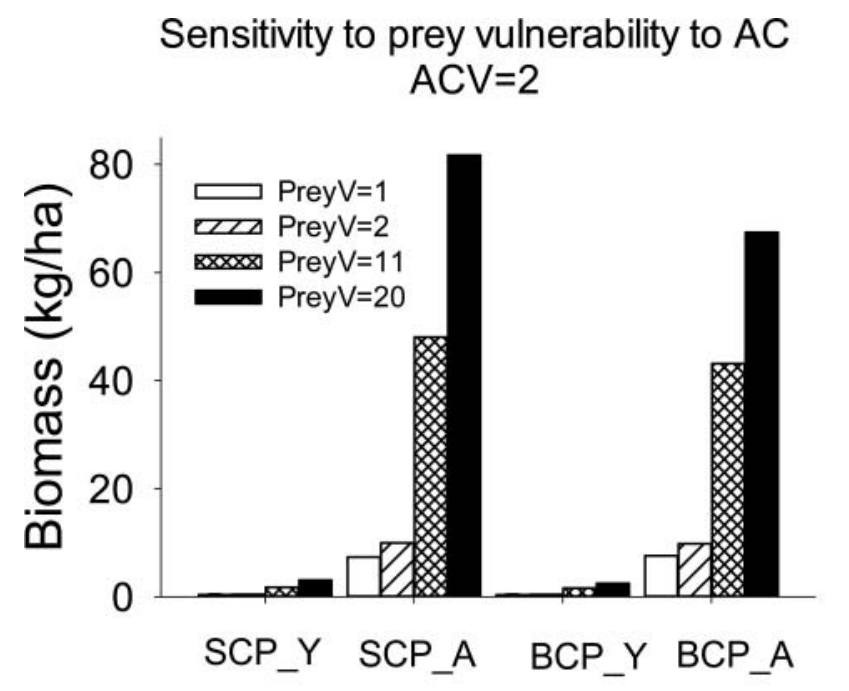

Sensitivity to vulnerability of young $A C$ to predators
PredV $=11$

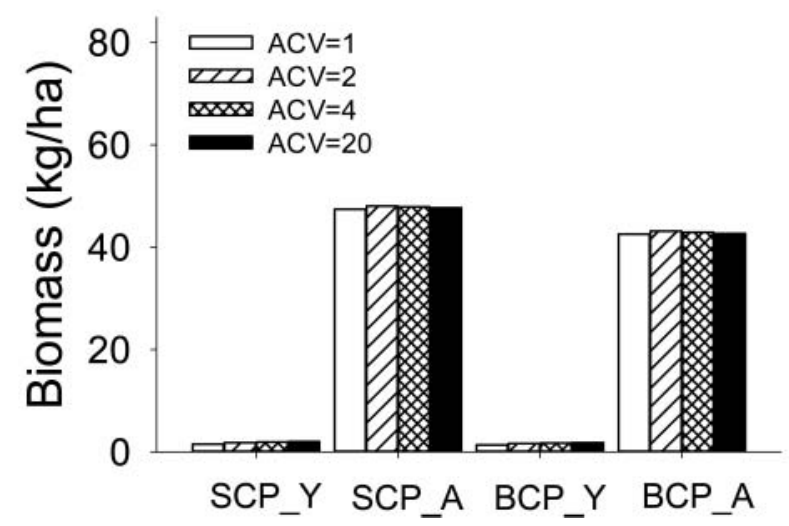

FIGURE 3. Sensitivity analysis of AC biomass to the vulnerability of prey to $\mathrm{AC}$ (PredV; top panel) and the vulnerability of young AC to predators (ACV; bottom panel). Other abbreviations are as follows: $\mathrm{SCP}_{-} \mathrm{Y}=$ young Silver Carp, SCP_A $=$ age-1+ Silver Carp, BCP_Y $=$ young Bighead Carp, and BCP_A $=$ age-1+ Bighead Carp.

Nutrient loading scenarios.-High nutrient loads without AC increased the biomass of most model groups in the food web due to higher food availability (Figure 6). The biomass of the piscivorous fish groups (juvenile and adult Walleyes, Rainbow Trout, and Smallmouth Bass) increased because of higher consumption of the greater prey biomass (Figure 7). Shiner biomass increased by $142 \%$ due to higher consumption of the increased zooplankton prey biomass (Figure 8). Several groups decreased in biomass. Juvenile Yellow Perch decreased by $48 \%$ due to higher predation by White Perch (up 474\%) on its larvae (which decreased 28\%) and age-0 stages (which decreased 57\%). Gizzard Shad decreased 51\% due to higher predation by adult Walleyes, White Perch, and White Bass (Figure 8 ). Adult Lake Trout decreased by $30 \%$ owing to the decrease in its major prey, Rainbow Smelt (which decreased by $22 \%$ ). Other lower-trophic groups increased by varying amounts in response to the higher phosphorus loads (Figure 6).

Under the high phosphorus loading scenario, AC reached a high equilibrium biomass (Figure 5). The biomass of juvenile and adult Walleyes increased by $9-11 \%$ due to the greater availability of food, including AC (Figures 6,7). The biomass of all Yellow Perch groups increased due to lower predation by White Perch and White Bass on larval and age-0 Yellow Perch and the higher biomass of benthic prey. The impacts of $\mathrm{AC}$ on other trophic groups under this scenario were similar to the impacts under the detrital scenarios.

\section{Food Web Responses to High AC Biomass}

In relatively few simulations, the $\mathrm{AC}$ biomass rose above $200 \mathrm{~kg} / \mathrm{ha}$ (Table A.2.3). The AC_HP scenario included seven runs with high AC biomass, the AC_ND scenario had no runs with high AC biomass, and each of the other scenarios had one run with high AC biomass. A high AC biomass had stronger positive and negative impacts on the biomass of other species, especially the negative impacts (Figure 10). For example, the biomass of adult Walleyes decreased by $31 \%$ under the AC_HD scenario and by $43 \%$ under the AC_LF scenario. That of adult Yellow Perch decreased by $35 \%$ under the AC_HD scenario and by $63 \%$ under the AC_LF scenario. Gizzard Shad experienced a decrease of $31 \%$ under the AC_LD scenario and one of 38\% under the AC_LF scenario. Emerald Shiners experienced a decrease of $84 \%$ under the AC_HD scenario, one of $49 \%$ under the AC_LD scenario, and one of 55\% under the AC_HP scenario. The biomass of juvenile Yellow Perch decreased by 65,28 , and $95 \%$, respectively, under the AC_HD, AC_LD, and AC_LF scenarios. The biomass of White Perch decreased as much as $78 \%$ under the AC_HD scenario. All zooplankton experienced decreases of $25 \%$ or more from baseline (Figure 10). For example, under the AC_HD scenario the biomass of herbivorous cladocerans decreased by $39 \%$, that of copepods by $46 \%$, that of rotifers by $56 \%$, and that of predaceous cladocerans by as much as $70 \%$. Consistent with the results in the section "Food Web Responses to AC Introduction" very few groups increased in biomass under any scenario, including larval and juvenile Yellow Perch, shiners, Gizzard Shad, Lake Whitefish, catfish (Channel Catfish Ictalurus punctatus and Brown Bullhead Ameiurus nebulosus), and chironomids.

\section{DISCUSSION}

\section{AC Impacts on the Food Web}

Imbalanced Ecopath models with AC invasion.-For multiple reasons, from $12 \%$ to $19 \%$ of the Ecopath models in our study were not balanced. Further investigation into why the models did not achieve mass balance revealed scenarios in 

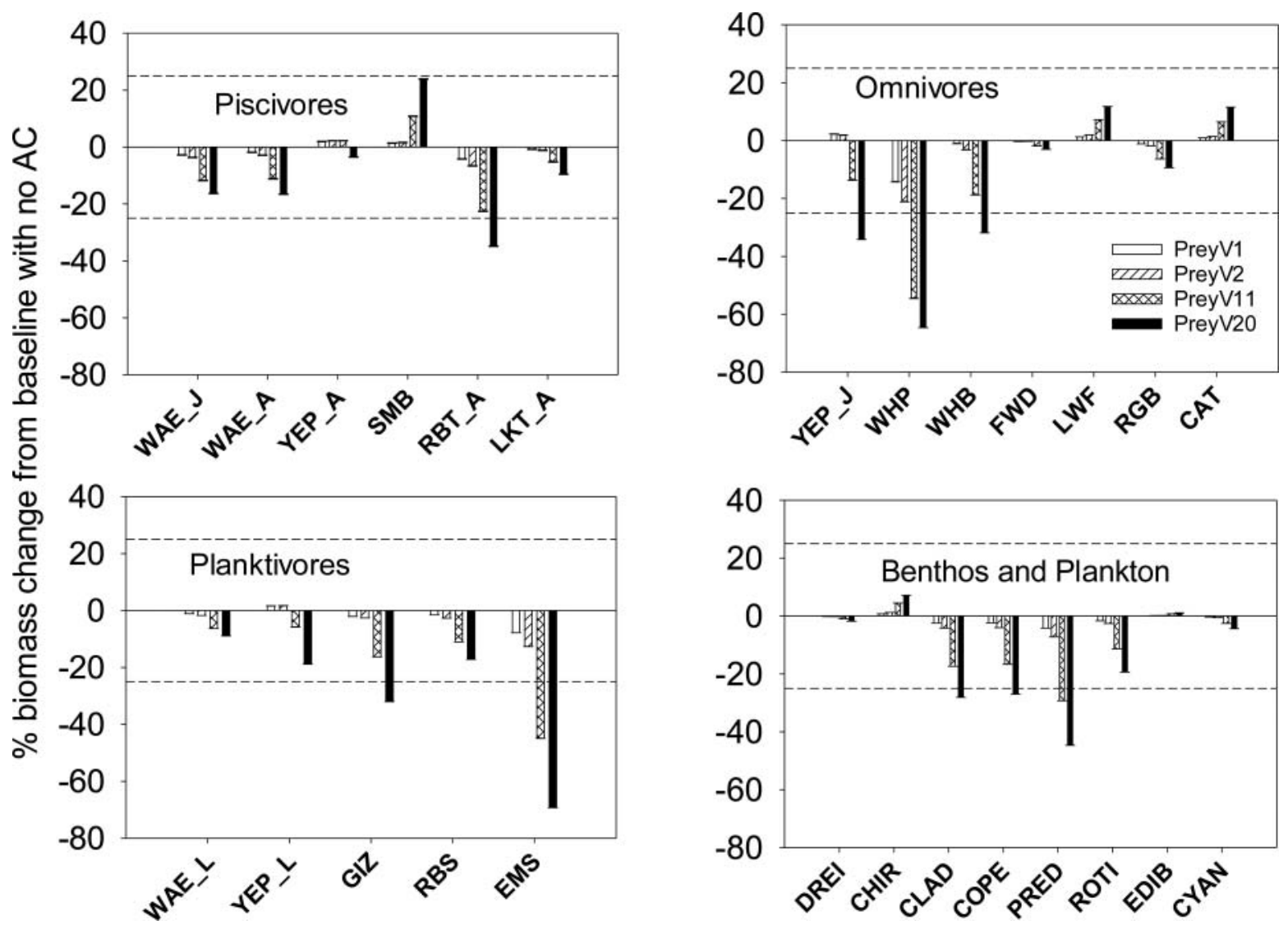

FIGURE 4. Percent biomass change from the baseline condition of no AC of model groups under different vulnerabilities of prey to AC (PreyV). In these simulations, the vulnerability of young AC to predators is 2 . The dashed lines represent $\pm 25 \%$ changes from the baseline condition.

which AC either failed to invade Lake Erie or had a substantial impact. Specifically, when the ecotrophic efficiency for zooplankton exceeds 1 AC can deplete zooplankton, which is a major concern of lake managers and scientists. Too heavy a degree of predation on age-0 AC suggests that they cannot invade a habitat in which the predation pressure is too high. In fact, one of the main differences between Lake Erie and the Illinois River is the higher relative abundance of predators in Lake Erie (see the discussion of predation on AC below). When $\mathrm{AC}$ respiration is less than $0, \mathrm{AC}$ will not have enough food to support their growth, although recent bioenergetics modeling suggests that there will be sufficient food in Lake Erie to support these two species (Cooke and Hill 2010; Anderson et al. 2015). The scenario in which the ecotrophic efficiency of larval Yellow Perch and Walleyes was greater than 1 indicates that $\mathrm{AC}$ predation on these larvae could cause these life stages and populations to crash. These conditions of mass imbalance suggest areas for further study.

Impacts from Ecosim models.-Relative to a baseline simulation with no $\mathrm{AC}$, most model simulations projected small decreases $(<25 \%)$ in the biomass of most piscivorous and planktivorous fishes and zooplankton with AC biomass levels of $50-100 \mathrm{~kg} / \mathrm{ha}$. The model results also suggest that $\mathrm{AC}$ will have minor effects on the benthos, phytoplankton, and bacteria in Lake Erie. Model projections of the effects of AC on most trophic levels were consistent across the phosphorus loading scenarios and across most of the detritus scenarios. Only White Perch, Gizzard Shad, shiners, and predatory cladocerans were substantially negatively affected by AC according to our threshold level of $25 \%$ change from the baseline (Kitchell et al. 2000). At high biomass levels ( $>200 \mathrm{~kg} / \mathrm{ha}$ ), our model results were consistent with observations of the negative effects of AC on planktivorous fishes in the lower Illinois River (Calkins et al. 2012; Garvey et al. 2012) and in countries where they have been introduced or are native (Costa-Pierce 1992).

Variation in the proportion of detritus in AC diets had little effect on the equilibrium biomass and ecological impacts of AC. Consumption of high levels of detritus produced essentially the same food web effects as consuming no detritus. This outcome is reasonable given that detritus was the largest biomass pool in the model and was not a major dietary component for most species groups. Several investigators (see Cudmore et al. 2012) report that AC can persist on diets of detritus when phytoplankton and zooplankton resources have been exhausted but that they do not grow well (Lin et al. 1981), and 

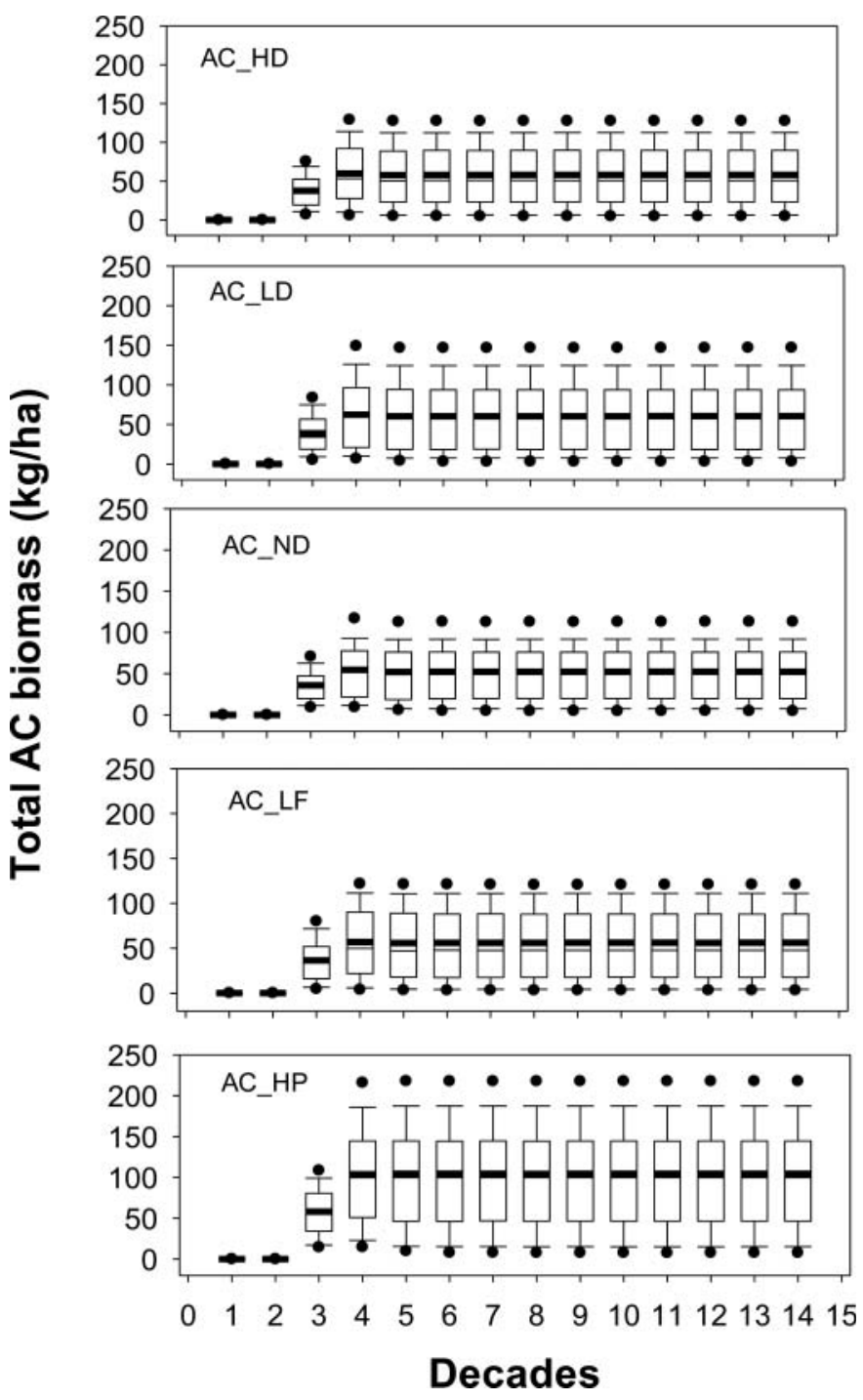

FIGURE 5. Simulated responses of total AC biomass (age-0 and age- $1+$ Silver and Bighead carp combined) to scenarios with different levels of detritus in AC diets, including high detritus in the AC diet (AC_HD), low detritus in the $\mathrm{AC}$ diet (AC_LD), and no detritus in the AC diet (AC_ND), along with larval fish in the AC diet (AC_LF), and high nutrient loads to Lake Erie (AC_HP). The box-and-whisker plots indicate the median values (thin black lines), 25th and 75th percentiles (tops and bottoms of the boxes), 10th and 90th percentiles (vertical lines), and 5th and 95th percentiles (black dots). The thick black lines represent the mean values of all Ecosim simulation runs. Note that $\mathrm{AC}$ were introduced into the model in the second decade.

our model results suggest no added benefit of organic detritus to $\mathrm{AC}$ growth when plankton are available.

In our model simulations, AC consumption of percid larvae caused the biomass of young life stages of Walleyes and Yellow Perch to decline and sometimes caused imbalances in the Ecopath model due to high predation mortality on Walleye larvae. Although we could find no direct evidence in the literature that $\mathrm{AC}$ eat fish larvae, adult $\mathrm{AC}$ might consume larvae through nonselective filter feeding (Costa-Pierce 1992). Our model results suggest that the biomass of all Yellow Perch life stages would decrease significantly under the larval fish predation scenario. Although there are reports of declines in larval Saugers Sander canadensis and Catlas Gibelion catla after the introduction of Silver Carp in other countries (Berthelmes 1984, cited in Costa-Pierce 1992), it is not clear whether this is due to direct predation by $\mathrm{AC}$ or competition for zooplankton prey. The potential for $\mathrm{AC}$ to consume larvae bears further investigation.

Nutrient loading had little influence on the effects of $\mathrm{AC}$ on the Lake Erie food web. In our model, higher nutrient loads acted to increase the biomass of all trophic groups, which buffered the effects of AC predation on lower trophic levels, decreased competition for food with other planktivores, and increased prey availability for piscivores. However, in contrast to the declines in biomass under other AC scenarios, the biomass of Walleyes and Yellow Perch increased under the AC_HP scenario. The biomass of Walleyes increased because of the substantial increase in prey provided by young AC, while that of Yellow Perch increased due to a higher biomass of young AC and Emerald Shiner prey and lower predation on Yellow Perch larvae by White Perch.

Asian carps had stronger effects on the Lake Erie food web when their biomass exceeded $200 \mathrm{~kg} / \mathrm{ha}$. These scenarios resulted in significant $(>25 \%)$ decreases in the biomass of most piscivore, planktivore, omnivore, and zooplankton taxa. The model generated high adult $\mathrm{AC}$ biomass when the average predation mortality on age-0 AC was relatively low (mean instantaneous annual predation mortality rate $=3.1$ ) and the average initial biomass of age-1+ $\mathrm{AC}$ was relatively high $(32.0 \mathrm{~kg} / \mathrm{ha})$; by contrast, it generated low adult AC biomass when the mean predation mortality rate was higher (4.0) and age-1+ biomass was lower ( $6.8 \mathrm{~kg} / \mathrm{ha})$. High AC biomass scenario results occurred infrequently (i.e., in only 10 of 428 simulations, or 2.3\%), suggesting that the Lake Erie food web as represented in our model is unlikely to support $\mathrm{AC}$ at the high biomass levels found in the Illinois and Mississippi rivers (Johnson and Hagerty 2008; Sass et al. 2014).

The Lake Erie food web may be less conducive to the high AC biomass levels that are found in the Mississippi and Illinois rivers. Comparison of the nutrient loads and biomass of lower trophic levels in these rivers (Johnson and Hagerty 2008; Sass et al. 2014) with those in Lake Erie (Munawar et al. 2008; Charlton et al. 2010) indicates that the IllinoisMississippi River habitats had higher phosphorus concentrations, higher levels of chlorophyll $a$, and lower zooplankton biomass before the AC invasion than are found in Lake Erie (Table A.2.4). Agency reports of the net catches of fish in the Illinois River suggest that prior to the AC invasion the ratio of planktivore to piscivore relative abundance was relatively high (5.9-8.2 : 1; McClelland et al. 2012), compared with 4:1 in Lake Erie (calculated based on the biomass in Table 1). The higher levels of nutrients and phytoplankton biomass and the lower predation pressure in the Illinois and Mississippi rivers 
a)

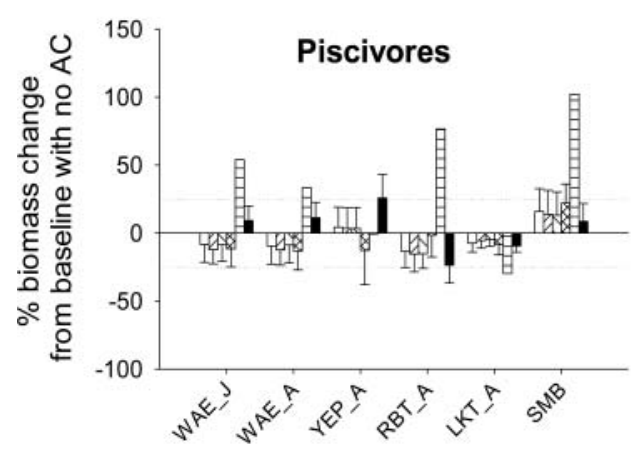

c)

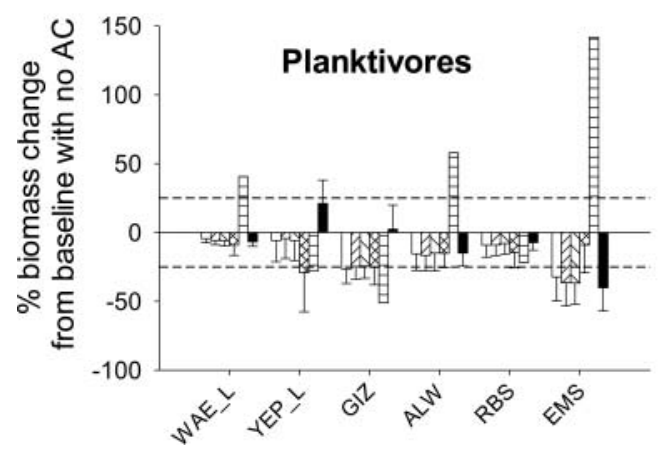

b)

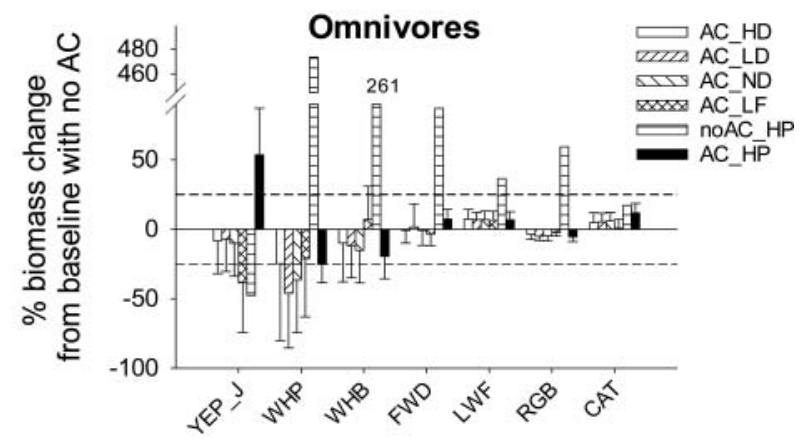

d)

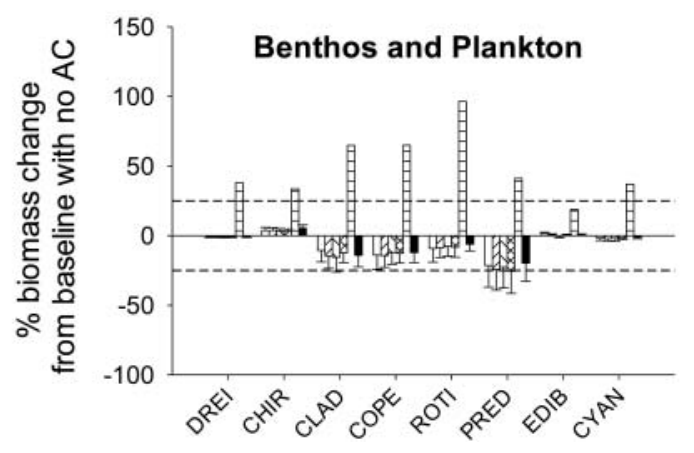

FIGURE 6. Mean percent change in biomass from the baseline condition of no AC for model groups with AC invasion under the following scenarios: AC_HD, AC_LD, AC_ND, AC_LF, noAC_HP (a high phosphorus load with no AC), and AC_HP. The dashed lines represent $\pm 25 \%$ changes from the baseline condition. Error bars $=$ SDs.

may result in higher AC population growth in those habitats. However, in the productive western basin of Lake Erie AC may reach high biomass levels and have more substantial effects on the food web than in the central and eastern basins.

Our model results for the effects on the food web of high AC biomass are similar in many respects to the reported impacts of AC in the Mississippi River drainage and elsewhere. In the Illinois River, Freedman et al. (2012) used stable isotope analysis to confirm diet overlap and potential competition between $\mathrm{AC}$ and native planktivores (Bluegill Lepomis macrochirus, Emerald Shiner, and Gizzard Shad) in areas where AC were most abundant. Garvey et al. (2012) and Sass et al. (2014) reported lower densities of copepods and cladocerans and higher densities of rotifers (due to predator release) in the Illinois River after the establishment of AC. The densities of other species in the lower Illinois River (Bigmouth Buffalo, White Bass, Black Crappie Pomoxis nigromaculatus, Freshwater Drum, Common Carp, and Sauger) also declined after the introduction of AC, likely as a result of competition for habitat and not for prey, as stable isotope analysis indicated less diet overlap with AC (Freedman et al. 2012). Gizzard Shad densities declined, but not substantially. The biomass densities of AC in the lower Illinois River were much higher (190-250 kg/ha) than those we simulated for Lake Erie (50-
$100 \mathrm{~kg} / \mathrm{ha}$ ), but they were within the peak biomass values in the simulations we ran (Garvey et al. 2012; David Glover, Ohio State University, personal communication). Garvey et al. (2012) reported no change in piscivore populations after AC became established in the Illinois River, although the diets of Largemouth Bass Micropterus salmoides included juvenile Silver Carp. In eutrophic lakes and reservoirs in Asia, Europe, and Israel (where AC have been introduced at high densities [>1,000 kg/ha]), AC have depleted large zooplankton grazers, leaving protozoans and small phytoplankton (Costa-Pierce 1992; Zhou et al. 2011). Thus, in most systems where AC have been introduced at high densities, their effects have been greatest on the zooplankton community and the life stages of fishes that depend on zooplankton. In Lake Erie, we predicted relatively low impacts of $\mathrm{AC}$ on the crustacean zooplankton community because AC caused a decrease in the biomass of predaceous cladocerans (e.g., spiny water fleas Bythotrephes spp.) and planktivorous fishes, which were the major source of mortality on zooplankton prior to the invasion. Thus, the release from planktivore predation likely mitigated the impacts of AC on zooplankton.

We found few differences between our model predictions of AC biomass and their impacts on Lake Erie and those reported by Wittmann et al. (2015). The experts 

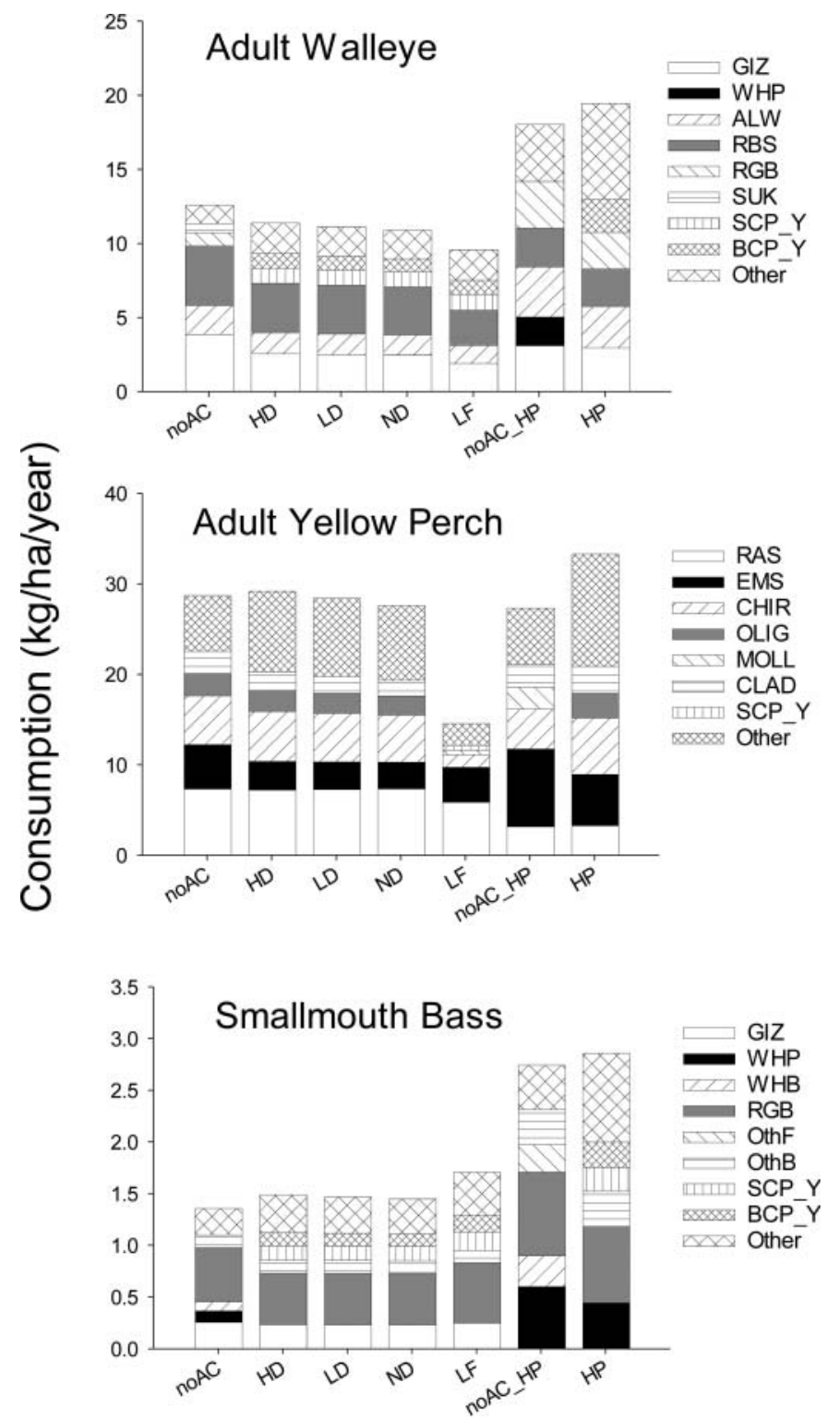

FIGURE 7. Prey consumption of three piscivores-adult Walleyes, adult Yellow Perch, and Smallmouth Bass-in the baseline simulation with no AC and under the scenarios described in Figure 6.

consulted by Wittmann et al. (2015) predicted that AC would reach an equilibrium biomass of $3.9-121.8 \mathrm{~kg} / \mathrm{ha}$, similar to the biomass range projected by our model. These experts also predicted that AC would have little impact on key species such as Walleyes, Gizzard Shad, and Rainbow Smelt and that the biomass of Yellow Perch would increase. Our model predicted minor declines for Walleyes and Rainbow Smelt under most of the simulation scenarios, and although it did not predict as large an increase in Yellow Perch biomass as Wittmann et al. (2015), our predictions for Yellow Perch adults consistently increased across simulation scenarios except for the larval predation scenario.

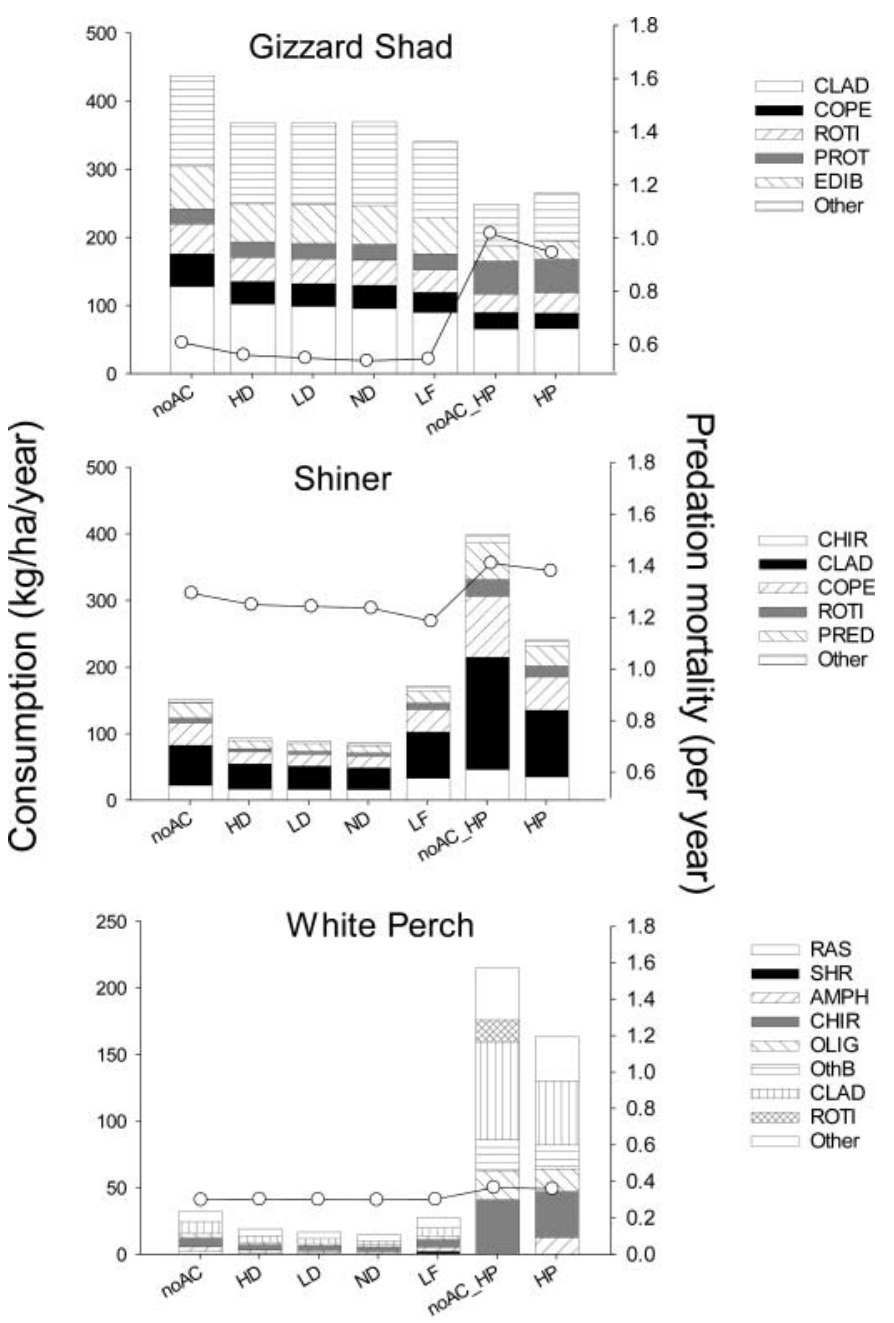

FIGURE 8. Prey consumption (bars) and annual predation mortality (lines) of Gizzard Shad, shiners, and White Perch in the baseline simulation with no $\mathrm{AC}$ and under the scenarios described in Figure 6.

Uncertainty analysis.-Asian carps can impact lower trophic levels and fish larvae at stocking densities exceeding $1,500 \mathrm{~kg} / \mathrm{ha}$ (see Costa-Pierce 1992 for a review; Zhou et al. 2011). Structured expert judgment helped us to estimate AC equilibrium biomass and the response of the Lake Erie food web to AC. The experts who were asked to define the equilibrium biomass of $\mathrm{AC}$ after their establishment estimated that AC would reach biomass levels similar to those of Gizzard Shad $(29.0 \mathrm{~kg} / \mathrm{ha})$, the most abundant planktivore species in Lake Erie (Wittmann et al. 2015). Our model simulations showed that at median equilibrium biomass and production AC would reach a biomass nearly twice as high as that of Gizzard Shad but that they would have relatively minor impacts on lower trophic levels in the Lake Erie food web. When the biomass of AC was high in our model (>200 kg/ha), the biomass of lower trophic levels decreased. The large variation around our model predictions resulted from the large range in 


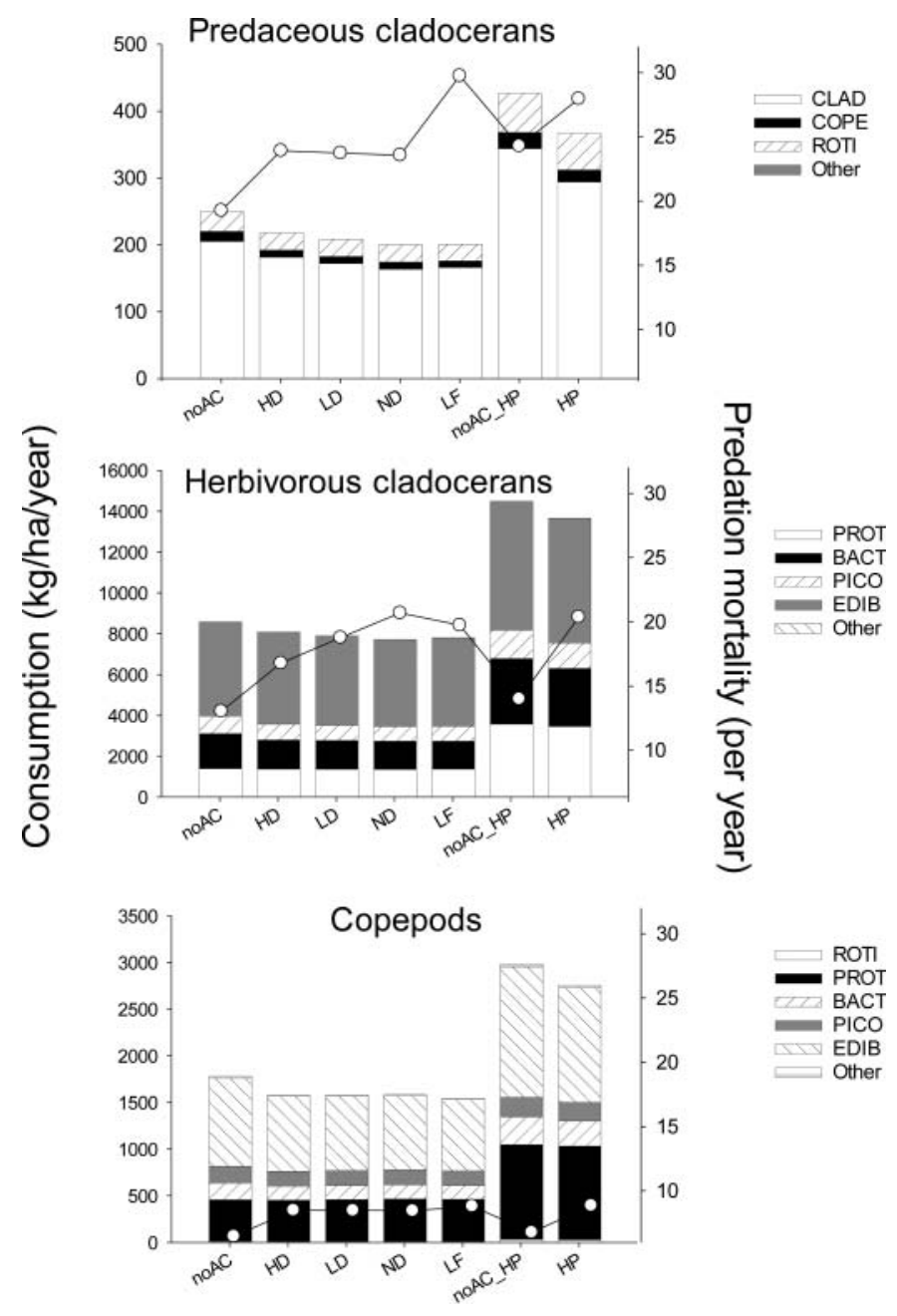

FIGURE 9. Prey consumption (bars) and annual predation mortality (lines) of predaceous cladocerans, herbivorous cladocerans, and copepods in the baseline simulation with no AC and under the scenarios described in Figure 6.

input values, which reflected the high uncertainty of experts concerning $\mathrm{AC}$ biomass, $P / B$, and the impacts on the Lake Erie food web.

Our assumption that SEJ estimates of the EwE input parameters followed a subjective probability distribution may have caused the high variability in the food web responses to AC. For example, the experts predicted that $P / B$ values would range from 0.84 to 3.61 for both AC species (Wittmann et al. 2015), which is logical given the uncertainty about AC performance in a new environment. However, empirical evidence suggests that $P / B$ values for large and long-lived species are unlikely to be at the higher end of this range based on general relationships between water temperature, maximum size, and growth rate (Pauly 1980). The wide range of input parameter values also contributed to the high variability around the mean responses to $\mathrm{AC}$ invasion.

The lack of data with which to consider the joint probabilities of model input parameters may have had an impact on our model results. The variability in our model projections of the impacts of AC may have been artificially low or high because we randomly and independently selected from subjective probability distributions of input parameter values to create balanced food web models before running our simulations. There is substantial evidence that life history traits (growth, mortality, and fecundity) are correlated; for example, high consumption rates $(Q / B$ values) are often correlated with high growth and mortality rates ( $P / B$ values) in fish (Stearns 1992); if the model input parameters were correlated, the variability in our model projections may have been lower or higher. Even so, our approach to incorporating uncertainty into the EwE food web model represents a substantial advancement over prior attempts to forecast the impacts of invasive species.

Model assumptions and biases.-Our model analysis may have been biased by several assumptions. First, we assumed that the modeled environment of Lake Erie was uniform, with no differences between nearshore and offshore communities or among basins. In reality, there are substantial differences in depth, productivity, habitat type, and temperature among Lake Erie's three basins that influence the vital rates of the species and assemblages that occur in each habitat. In particular, AC may reach higher biomasses $(>200 \mathrm{~kg} / \mathrm{ha}$ ) and have greater local impacts on the food web of Lake Erie's western basin than is reflected in the general results of our model (Figure 6). Moreover, our model environment did not include the tributary habitats that are common to western Lake Erie and that influence the recruitment and production dynamics of AC and other species (Reichert et al. 2010; Cudmore et al. 2012).

We also assumed that predators had access to young AC throughout the year. However, young AC are known to reside in wetlands for much of their first year, and as a consequence may not be available to some predators during that time. Nevertheless, there are few remaining coastal wetlands in Lake Erie (Kowalski and Wilcox 1999), so young AC likely would inhabit shallow nearshore areas and be available to the adult predators in our model (Walleyes, Yellow Perch, and piscivorous birds) and others (Northern Pike Esox lucius and Largemouth Bass) not included in our model. Studies of Grass Carp Ctenopharyngodon idella in ponds and small lakes indicate that predators such as Largemouth Bass preferentially consume them over smaller prey (Rottmann 1977). Many of the Lake Erie piscivores identified through SEJ that would consume juvenile AC before they outgrow predator gape size are present (Northern Pike) or have congeners or functional equivalents in Russia (Zander Sander lucioperca, Eurasian Perch Perca fluviatilis, and Ide Leuciscus idus [Negonovskaya 1980]) and in China (Chinese Perch Siniperca chuatsi [Liang et al. 2008]) that are known to consume and control AC populations.

We ran simulations of the impacts of $\mathrm{AC}$ assuming that their prey have the same vulnerability to AC as to Gizzard Shad. Our analysis indicated that prey vulnerability would greatly affect the biomass of AC and their impacts. If plankton 

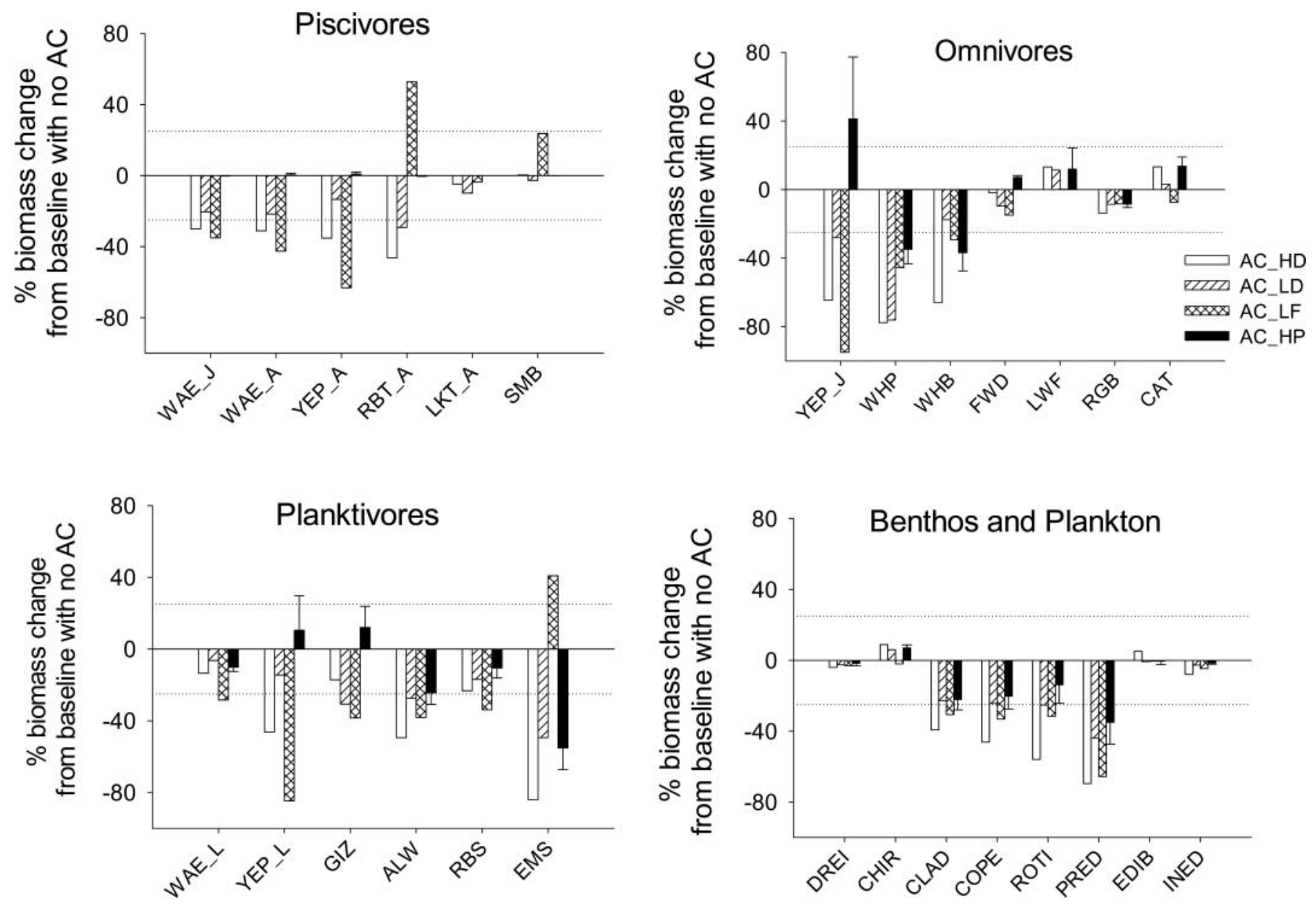

FIGURE 10. Mean percent change in biomass from the baseline condition of no AC for model groups with high AC biomass ( $>200 \mathrm{~kg} / \mathrm{ha})$ under the scenarios described in Figure 6 . The dashed lines represent $\pm 25 \%$ changes from the baseline condition. Error bars $=$ SDs.

prey are more or less vulnerable to AC than they are to Gizzard Shad, we will have under- or overestimated AC biomass and its impacts on the food web. Our model results were less sensitive to variability in the assumptions about the vulnerability of young $\mathrm{AC}$ to piscivores. Also not considered were the uncertainties in vulnerabilities inherent in resident species' predator-prey interactions. Such uncertainties may influence the overall impacts of AC on the food web. For example, if the vulnerability of Gizzard Shad to Walleyes is higher than we assumed - and thus the population dynamics of the two species are more tightly coupled - any change in Gizzard Shad biomass caused by $\mathrm{AC}$ will have greater impacts on Walleye biomass than were predicted by our model. We also assumed that the vulnerabilities of prey to predators were constant throughout the simulation. Langseth et al.'s (2012) method 4 indicated that the vulnerabilities associated with invasive species may change (especially at the beginning of the invasion) and can be calibrated with a biomass time series of the invasive species. However, we do not have time series data for an $\mathrm{AC}$ invasion of Lake Erie with which to define their prey vulnerabilities because AC have not yet invaded. More studies of the vulnerabilities of prey to $\mathrm{AC}$ are needed.

We assumed that the range of values for the Ecopath input parameters provided by the experts represents the likely growth, mortality (or $P / B$ ), and consumption of $\mathrm{AC}$ in Lake Erie. However, the range of the values they provided was much greater than in a recently conducted meta-analysis of AC vital rates and life history (Tsehaye et al. 2013 [see their Table 2]). If AC become established in Lake Erie and their mortality is lower than predicted by the experts, our model results will have underestimated the biomass of $\mathrm{AC}$ and their impacts on the food web.

Finally, we assumed that the biomass of dreissenids (tissue only) was $3,181 \mathrm{~kg} / \mathrm{ha}$, an intermediate value between its peak biomass (approximately 6,753 kg/ha) in 2004 and a more recent value of approximately $1,115 \mathrm{~kg} / \mathrm{ha}$ in 2011 (Karatayev et al. 2014). We anticipate that dreissenid biomass will continue to fluctuate over time as it approaches equilibrium levels. If dreissenid mussels continue to decline, our model results may underestimate the equilibrium biomass and potential 
impacts of $\mathrm{AC}$ because these mussels may compete with $\mathrm{AC}$ for plankton prey.

\section{Conclusions and Future Work}

The biomass of AC and their impacts on lower trophic levels were consistent in direction with but lower in magnitude than those observed in the Illinois River. Of course, changes in the lower part of the food web may be of direct concern to some stakeholders (e.g., baitfish harvesters and proponents of native biodiversity) and the impacts could be greater than average in some parts of Lake Erie, but in general our results suggest that the lakewide impacts on the Lake Erie food web will not be as great as some have feared as long as AC do not consume the larvae of percid sport fishes.

However, SEJ and our model results revealed that the high degree of uncertainty surrounding some parameter values (especially AC mortality rates, the vulnerability of prey to AC, the vulnerability of age- $0 \mathrm{AC}$ to piscivores, equilibrium biomass, and the magnitude of predation by $\mathrm{AC}$ on the larvae of piscivorous fish species) produces a high degree of uncertainty about the overall impact of $\mathrm{AC}$ on the food web. The error around the mean response to the introduction of $\mathrm{AC}$ was often as great as the mean itself. Additionally, even if the average model outcome applies to much of Lake Erie, there are likely parts of the lake-perhaps including parts that are important for fisheries or other human uses-that would experience the severe outcomes that occurred in some model simulations. Future research that narrows the uncertainty of key parameter estimates and considers the spatial heterogeneity of Lake Erie would greatly benefit those making decisions about Great Lakes management and policy.

Finally, managers and policymakers need to consider in greater detail how changes in the food web and other impacts that we did not consider may affect the public. A food web impact that is small from a lakewide fishery perspective may nevertheless shift the spatial distribution of ecosystem services or cause a large economic impact on one or more stakeholder groups. Also of importance are the risks that AC may pose to ecosystem services and economic activities that are not linked directly to food web impacts. Numerous Silver Carp jumping in response to recreational boats and jet skis could produce large changes in human use of Lake Erie independent of any food web impacts, as has occurred in the Mississippi River basin (Charlebois and Tepas 2011; Thomas et al. 2011). Overall, future considerations of the impacts of $\mathrm{AC}$ at Lake Erie and other Great Lakes would benefit from an evaluation of the bioeconomic cost of invasions; this could be done by dynamically linking the EwE model to other frameworks for economic assessment (such as a computable general equilibrium economic model) to determine the regional economic costs of a biological perturbation to an ecosystem and the human uses of that ecosystem.

\section{ACKNOWLEDGMENTS}

We acknowledge financial support from the U.S. Environmental Protection Agency's (EPA) Great Lakes Restoration Initiative, NOAA Center for Sponsored Coastal Ocean Research awards NA09NOS4780192 and NA10NOS4780218, and National Science Foundation CNIC award 1322540. We thank a select group of internal reviewers (Roy Stein, William Pine, Kenneth Rose, and Bryan Kinter) and three anonymous reviewers, all of whose comments substantially improved earlier drafts of the manuscript. We also appreciate access to data collected by Lake Erie monitoring agencies (EPA's Great Lakes National Program Office, Ohio Department of Natural Resources, Michigan Department of Natural Resources, New York State Department of Environmental Conservation, U.S. Geological Survey, and Ontario Ministry of Natural Resources). We thank V. Christensen, S. Lai, and J. Steenbeek for model consultation. Initial development of the Lake Erie Ecopath model was done by coauthors X. Zhu and T. B. Johnson and supported by the Canada-Ontario agreement Respecting the Great Lakes Basin Ecosystem. This is NOAA Great Lakes Environmental Research Laboratory contribution 1788.

\section{REFERENCES}

Ahrens, R. N. M., C. J. Walters, and V. Christensen. 2012. Foraging arena theory. Fish and Fisheries 13:41-59.

Anderson, K. R., D. C. Chapman, T. T. Wynne, K. Masagounder, and C. P. Paukert. 2015. Suitability of Lake Erie for bigheaded carps based on bioenergetic models and remote sensing. Journal of Great Lakes Research 41:358-366.

Aspinall, W. 2010. A route to more tractable expert advice. Nature 463:294295.

Bartell, S. M., J. E. Breck, R. H. Gardner, and A. L. Brenkert. 1986. Individual parameter perturbation and error analysis of fish bioenergetics models. Canadian Journal of Fisheries and Aquatic Sciences 43:160-168.

Berthelmes, D. 1984. Heavey Silver Carp (Hypophtalmichthys molitrix [Val.]) stocking in lakes and its influence on indigenous fish stocks. EIFAC Technical Paper 42 283(Supplement 2):313-324.

Blukacz-Richards, E. A., and M. A. Koops. 2012. An integrated approach to identifying ecosystem recovery targets: application to the Bay of Quinte. Aquatic Ecosystem Health and Management 15:464-472.

Bolsenga, S. J., and C. E. Herdendorf. 1993. Lake Erie and Lake St. Clair handbook. Wayne State University Press, Detroit, Michigan.

Boros, G., A. Mozsár, Z. Vitál, A. S. Nagy, and A. Specziár. 2014. Growth and condition factor of hybrid (Bighead Hypophthalmichthys nobilis Richardson, $1845 \times$ Silver Carp H. molitrix Valenciennes, 1844) Asian carps in the shallow, oligo-mesotrophic Lake Balaton. Journal of Applied Ichthyology 30:546-548.

Branch, G. M., and C. N. Steffani. 2004. Can we predict the effects of alien species? A case history of the invasion of South Africa by Mytilus galloprovincialis (Lamarck). Journal of Experimental Marine Biology and Ecology 300:189-215

Calkins, H. A., S. J. Tripp, and J. E. Garvey. 2012. Linking Silver Carp habitat selection to flow and phytoplankton in the Mississippi River. Biological Invasions 14:949-958.

Charlebois, P. M., and K. M. Tepas. 2011. Comprehensive plan for increasing effectiveness of Bighead and Silver carp outreach. Pages 191-198 in D. C. Chapman and M. H. Hoff, editors. Invasive Asian carps in North America. American Fisheries Society, Symposium 74, Bethesda, Maryland. 
Charlton, M., J. Vincent, C. Marvin, and J. Ciborowski. 2010. Status of nutrients in the Lake Erie basin. Prepared by the Lake Erie Nutrient Science Task Group for the Lake Erie Lakewide Managment Plan, Windsor, Ontario. Available: http://www.epa.gov/lakeerie/erie_nutrient_2010.pdf. (December 2014).

Chen, S. 1982. [Studies on the feeding spectrum of Silver Carp and Bighead Carp fingerlings in Lake Donghu (China).] Reservoir Fisheries of China 3:21-26 (In Chinese.)

Chick, J. H., and M. A. Pegg. 2001. Invasive carp in the Mississippi River basin. Science 292:2250-2251.

Christensen, V., and C. J. Walters. 2004. Ecopath with Ecosim: methods, capabilities, and limitations. Ecological Modelling 172:109-139.

Christensen, V., C. J. Walters, and D. Pauly. 2005. Ecopath with Ecosim: a user's guide. University of British Columbia, Fishereis Centre, Vancouver.

Cooke, R. 1991. Experts in uncertainty: opinion and subjective probability in science. Oxford University Press, New York.

Cooke, R. M., M. E. Wittmann, D. M. Lodge, J. D. Rothlisberger, E. S. Rutherford, H. Zhang, and D. M. Mason. 2014. Out-of-sample validation for structured expert judgment of Asian carp establishment in Lake Erie. Integrated Environmental Assessment and Management 10:522-528.

Cooke, S. L., and W. R. Hill. 2010. Can filter-feeding Asian carp invade the Laurentian Great Lakes? A bioenergetic modelling exercise. Freshwater Biology 55:2138-2152.

Costa-Pierce, B. A. 1992. Riview of the spawning requirements and feeding ecology of Silver Carp (Hypophthalmichthys molitrix) and reevaluation of its use in the fisheries and aquaculture. Reviews in Aquatic Sciences 6:257273.

Cudmore, B. C., N. E. Mandrak, J. M. Dettmers, D. C. Chapman, and C. S. Kolar. 2012. Bionational ecological risk assessment of bigheaded carps (Hypophthalmichthys spp.) for the Great Lakes basin. Canadian Science Advisory Secretariat Research Document 2011/114.

DeGrandchamp, K. L., J. E. Garvey, and R. E. Colombo. 2008. Movement and habitat selection by invasive Asian carps in a large river. Transactions of the American Fisheries Society 137:45-56.

DeGrandchamp, K. L., J. E. Garvey, and L. A. Csoboth. 2007. Linking adult reproduction and larval density of invasive carp in a large river. Transactions of the American Fisheries Society 136:1327-1334.

Dick, J. T. A., K. Gallagher, S. Avlijas, H. C. Clarke, S. E. Lewis, S. Leung, D. Minchin, J. Caffrey, M. E. Alexander, C. Maguire, C. Harrod, N. Reid, N. R. Haddaway, K. D. Farnsworth, M. Penk, and A. Ricciardi. 2013. Ecological impacts of an invasive predator explained and predicted by comparative functional responses. Biological Invasions 15:837-846.

Dolan, D. M., and S. C. Chapra. 2012. Great Lakes total phosphorus revisited, 1. Loading analysis and update (1994-2008). Journal of Great Lakes Research 38:730-740.

Freedman, J. A., S. E. Butler, and D. H. Wahl. 2012. Impacts of invasive Asian carps on native food webs. Final project report to Illinois-Indiana Sea Grant. University of Illinois, Sullivan.

Garvey, J. E., G. G. Sass, J. Trushenski, and D. Glover. 2012. Fishing down the Bighead and Silver carps: reducing the risk of invasion to the Great Lakes. Illinois Department of Natural Resources, Carbondale.

Goossens, L. H. J., R. M. Cooke, A. R. Hale, and L. Rodic-Wiersma. 2008. Fifteen years of expert judgement at TUDelft. Safety Science 46:234-244.

Havens, K. E., T. Kukushima, P. Xie, T. Iwakuma, R. T. James, N. Takamura, T. Hanazato, and T. Yamamoto. 2001. Nutrient dynamics and the eutrophication of shallow Lakes Kasumigaura (Japan), Donghu (PR China), and Okeechobee (USA). Environmental Pollution 111:263-272.

Irons, K. S., G. G. Sass, M. A. McClelland, and T. M. O'Hara. 2011. Bigheaded carp invasion of the La Grange Reach of the Illinois River: insights from the Long-Term Resource Monitoring Program. Pages 3150 in D. C. Chapman and M. H. Hoff, editors. Invasive Asian carps in North America. American Fisheries Society, Symposium 74, Bethesda, Maryland.
Jerde, C. L., W. L. Chadderton, A. R. Mahon, M. A. Renshaw, J. Corush, M. L. Budny, S. Mysorekar, and D. M. Lodge. 2013. Detection of Asian carp DNA as part of a Great Lakes basinwide surveillance program. Canadian Journal of Fisheries and Aquatic Sciences 70:522-526.

Jerde, C. L., A. R. Mahon, W. L. Chadderton, and D. M. Lodge. 2011. "Sightunseen" detection of rare aquatic species using environmental DNA. Conservation Letters 4:150-157.

Johnson, B. L., and K. H. Hagerty. 2008. Status and trends of selected resources of the upper Mississippi River system. U.S. Geological Survey, Technical Report LTRMP 2008-T002, Reston, Virginia.

Kao, Y.-C., S. Adlerstein, and E. Rutherford. 2014. The relative impacts of nutrient loads and invasive species on a Great Lakes food web: an Ecopath with Ecosim analysis. Journal of Great Lakes Research 40(Supplement 1):35-52.

Karatayev, A. Y., L. E. Burlakova, C. Pennuto, J. Ciborowski, V. A. Karatayev, P. Juette, and M. Clapsadl. 2014. Twenty-five years of changes in Dreissena spp. populations in Lake Erie. Journal of Great Lakes Research 40:550-559.

Kelly, A. M., C. R. Engle, M. L. Armstrong, M. Freeze, and A. J. Mitchell. 2011. History of introductions and governmental involvement in promoting the use of Grass, Silver, and Bighead carps. Pages 163-174 in D. C. Chapman and M. H. Hoff, editors. Invasive Asian carp in North America. American Fisheries Society, Symposium 74, Bethesda, Maryland.

Kitchell, J. F., S. P. Cox, C. J. Harvey, T. B. Johnson, D. M. Mason, K. K. Schoen, K. Aydin, C. Bronte, M. Ebener, M. Hansen, M. Hoff, S. Schram, D. Schreiner, and C. J. Walters. 2000. Sustainability of the Lake Superior fish community: interactions in a food web context. Ecosystems 3:545-560.

Kocovsky, P. M., D. C. Chapman, and J. E. McKenna. 2012. Thermal and hydrologic suitability of Lake Erie and its major tributaries for spawning of Asian carps. Journal of Great Lakes Research 38:159-166.

Kolar, C. S., and D. M. Lodge. 2002. Ecological predictions and risk assessment for alien fishes in North America. Science 298:1233-1236.

Koonce, J. F., W. D. N. Busch, and T. Czapla. 1996. Restoration of Lake Erie: contribution of water quality and natural resource management. Canadian Journal of Fisheries and Aquatic Sciences 53:105-112.

Kowalski, K., and D. Wilcox. 1999. Use of historical and geospatial data to guide the restoration of a Lake Erie coastal marsh. Wetlands 19:858-868.

Kulhanek, S. A., A. Ricciardi, and B. Leung. 2011. Is invasion history a useful tool for predicting the impacts of the world's worst aquatic invasive species? Ecological Applications 21:189-202.

Langseth, B. J., M. Rogers, and H. Zhang. 2012. Modeling species invasions in Ecopath with Ecosim: an evaluation using Laurentian Great Lakes models. Ecological Modelling 247:251-261.

Liang, X.-F., X. Lin, S. Li, and J.-K. Liu. 2008. Impact of environmental and innate factors on the food habits of Chinese perch Siniperca chuatsi (Basilewsky) (Percichthyidae). Aquacuture Research 39:150-157.

Lin, W. L., X. Z. Liu, and J. K. Liu. 1981. Detritus formation of two plankters and query on the role of their detritus in the nutrition of the Silver Carp and Bighead Carp. Internationale Vereinigung fuer Theoretische und Angewandte Limnologie Verhandlungen 212:1287-1290.

Liu, X.-J., X.-Q. Xu, P. Xie, and N. Takamura. 2000. Seasonal changes of dissolved and particulate organic carbon in Donghu Lake, China. Chinese Journal of Oceanology and Limnology 18:372-377.

Madenjian, C. P., E. S. Rutherford, C. A. Stow, E. F. Roseman, and J. X. He. 2013. Trophic shift, not collapse. Environmental Science and Technology 47:11915-11916.

McClelland, M. A., G. G. Sass, T. R. Cook, K. S. Irons, N. N. Michaels, T. M. O'Hara, and C. S. Smith. 2012. The long-term Illinois River fish population monitoring program. Fisheries 37:340-350.

Michalak, A. M., E. J. Anderson, D. Beletsky, S. Boland, N. S. Bosch, T. B. Bridgeman, J. D. Chaffin, K. Cho, R. Confesor, I. Daloglu, J. V. DePinto, M. A. Evans, G. L. Fahnenstiel, L. L. He, J. C. Ho, L. Jenkins, T. H. Johengen, K. C. Kuo, E. LaPorte, X. J. Liu, M. R. McWilliams, M. R. Moore, D. J. Posselt, R. P. Richards, D. Scavia, A. L. Steiner, E. Verhamme, D. M. 
Wright, and M. A. Zagorski. 2013. Record-setting algal bloom in Lake Erie caused by agricultural and meteorological trends consistent with expected future conditions. Proceedings of the National Academy of Sciences of the USA 110:6448-6452.

Morrison, B. J., J. C. Casselman, T. B. Johnson, and D. L. Noakes. 2004. New Asian carp genus (Hypophthalmichthys) in Lake Erie. Fisheries 29(8):6-7.

Munawar, M., I. F. Munawar, M. Fitzpatrick, H. Niblock, K. Bowen, and J. Lorimer. 2008. An intensive assessment of planktonic communities in the Canadian waters of Lake Erie, 1998. Pages 297-346 in M. Munawar and R. Heath, editors. Checking the pulse of Lake Erie. Aquatic Ecosystem Health and Management Society, Burlington, Ontario.

Murphy, E. A., and P. R. Jackson. 2013. Hydraulic and water quality data collection for the investigation of Great Lakes tributaries for Asian carp spawning and egg transport suitability. U.S. Geological Survey, Scientific Investigations Report 2013-5106, Reston, Virginia.

Negonovskaya, I. T. 1980. On the results and prospects of the introduction of phytophagous fishes into waters of the USSR. Journal of Ichthyology 20:101-111.

Oldenburg, K., M. A. Stapanian, P. A. Ryan, and E. Holm. 2007. Potential strategies for recovery of Lake Whitefish and Lake Herring stocks in eastern Lake Erie. Journal of Great Lakes Research 33:46-58.

Pauly, D. 1980. On the interrelationships between natural mortality, growth parameters, and mean environmental temperature in 175 fish stocks. Journal du Conseil Conseil International pour l'Exploration de la Mer 39:175-192.

Pine, W. E., T. J. Kwak, and J. A. Rice. 2007. Modeling management scenarios and the effects of an introduced apex predator on a coastal riverine fish community. Transactions of the American Fisheries Society 136:105-120.

Pinnegar, J. K., M. T. Tomczak, and J. S. Link. 2014. How to determine the likely indirect food web consequences of a newly introduced nonnative species: a worked example. Ecological Modelling 272:379-387.

Reichert, J. M., B. J. Fryer, K. L. Pangle, T. B. Johnson, J. T. Tyson, A. B. Drelich, and S. A. Ludsin. 2010. River-plume use during the pelagic larval stage benefits recruitment of a lentic fish. Canadian Journal of Fisheries and Aquatic Sciences 67:987-1004.

Ricciardi, A. 2003. Predicting the impacts of an introduced species from its invasion history: an empirical approach applied to zebra mussel invasions. Freshwater Biology 48:972-981.

Ricciardi, A. 2006. Patterns of invasion in the Laurentian Great Lakes in relation to changes in vector activity. Diversity and Distributions 12:425-433.

Ricciardi, A., M. F. Hoopes, M. P. Marchetti, and J. L. Lockwood. 2013. Progress toward understanding the ecological impacts of nonnative species. Ecological Monographs 83:263-282.

Ricciardi, A., and R. Kipp. 2008. Predicting the number of ecologically harmful exotic species in an aquatic system. Diversity and Distributions 14:374-380.

Rothlisberger, J. D., D. C. Finnoff, R. M. Cooke, and D. M. Lodge. 2012. Shipborne nonindigenous species diminish Great Lakes ecosystem services. Ecosystems 15:462-476.

Rottmann, R. 1977. Management of weedy lakes and ponds with Grass Carp. Fisheries 2(5):8-14.

Sampson, S. J., J. H. Chick, and M. A. Pegg. 2009. Diet overlap among two Asian carp and three native fishes in backwater lakes on the Illinois and Mississippi rivers. Biological Invasions 11:483-496.

Sass, G. G., C. Hinz, A. C. Erickson, N. N. McClelland, M. A. McClelland, and J. M. Epifanio. 2014. Invasive Bighead and Silver carp effects on zooplankton communities in the Illinois River, Illinois, USA. Journal of Great Lakes Research 40:911-921.

Schrank, S. J., C. S. Guy, and J. F. Fairchild. 2003. Competitive interactions between age-0 Bighead Carp and Paddlefish. Transactions of the American Fisheries Society 132:1222-1228.

Smith, R. E. H., V. P. Hiriart-Baer, S. N. Higgins, S. J. Guildford, and M. N. Charlton. 2005. Planktonic primary production in the offshore waters of dreissenid-infested Lake Erie in 1997. Journal of Great Lakes Research 31 (Supplement 2):50-62.

Snyder, R. J., L. E. Burlakova, A. Y. Karatayev, and D. B. MacNeill. 2014. Updated invasion risk assessment for Ponto-Caspian fishes to the Great Lakes. Journal of Great Lakes Research 40:360-369.

Stearns, S. C. 1992. The evolution of life histories. Oxford Univeristy Press, New York.

Thomas, R. G., J. A. Jenkins, and J. David. 2011. Occurrence and distribution of Asian carps in Louisiana. Pages 239-250 in D. C. Chapman and M. H. Hoff, editors. Invasive Asian carps in North America. American Fisheries Society, Symposium 74, Bethesda, Maryland.

Tsehaye, I., M. Catalano, G. Sass, D. Glover, and B. Roth. 2013. Prospects for fishery-induced collapse of invasive Asian carp in the Illinois River. Fisheries 38:445-454.

Upsdell, B. L. 2005. The carbon and nitrogen composition of suspended particulate matter in Lake Erie, selected tributaries, and its outflow. University of Waterloo, Waterloo, Ontario.

Walters, C., S. J. D. Martell, V. Christensen, and B. Mahmoudi. 2008. An Ecosim model for exploring Gulf of Mexico ecosystem management options: implications of including multistanza life history models for policy predictions. Bulletin of Marine Science 83:251-271.

Wang, H. Y., D. W. Einhouse, D. G. Fielder, L. G. Rudstam, C. S. Vandergoot, A. J. VanDeValk, T. G. Zorn, and T. O. Höök. 2012. Maternal and stock effects on egg size variation among Walleye Sander vitreus stocks from the Great Lakes region. Journal of Great Lakes Research 38:477-489.

Wang, H. Y., E. S. Rutherford, H. A. Cook, D. W. Einhouse, R. C. Haas, T. B. Johnson, R. Kenyon, B. Locke, and M. W. Turner. 2007. Movement of Walleyes in Lakes Erie and St. Clair inferred from tag return and fisheries data. Transactions of the American Fisheries Society 136:539-551.

Williamson, C. J., and J. E. Garvey. 2005. Growth, fecundity, and diets of newly established Silver Carp in the middle Mississippi River. Transactions of the American Fisheries Society 134:1423-1430.

Wittmann, M. E., R. M. Cooke, J. D. Rothlisberger, and D. M. Lodge. 2014. Using structured expert judgment to assess invasive species prevention: Asian carp and the Mississippi-Great Lakes hydrologic connection. Environmental Science and Technology 48:2150-2156.

Wittmann, M. E., R. M. Cooke, J. D. Rothlisberger, E. S. Rutherford, H. Zhang, D. M. Mason, and D. M. Lodge. 2015. Use of structured expert judgment to forecast invasions by Bighead and Silver carp in Lake Erie. Conservation Biology 29:187-197.

Zhou, G. J., X. M. Zhao, Y. H. Bi, and Z. Y. Hu. 2011. Effects of Silver Carp (Hypophthalmichthys molitrix) on spring phytoplankton community structure of Three Gorges Reservoir (China): results from an enclosure experiment. Journal of Limnology 70:26-32. 


\section{Appendix A.1: P/B Values for Asian Carps}

This section describes how we partitioned the total $P / B$ values predicted by experts into values for young-of-year and age-1+ Asian carps (AC).

Survival rates for AC from time $t_{1}$ to time $t_{2}$ were calculated as

$$
\frac{N_{t 2}}{N_{t 1}}=e^{-(t 2-t 1) Z}
$$

where $Z$ is the total instantaneous mortality rate (i.e., $P / B$ ) and $t$ is age. Since age- 0 fish live from 0 to 1 year, equation (A.1.1) becomes

$$
\frac{N_{1}}{N_{0}}=e^{-(1-0)(P / B)_{Y}}
$$

For age-1+ fish, equation (A.1.1) becomes

$$
\frac{N_{\operatorname{tmax}}}{N_{1}}=e^{-(\operatorname{tmax}-1)(P / B)_{A}},
$$

where $t_{\max }=$ the maximum lifespan (20 years for Bighead Carp and 15 years for Silver Carp; www.fishbase.org).

For the whole population, equation (A.1.1) therefore becomes

$$
\frac{N_{\text {tmax }}}{N_{0}}=e^{-(\operatorname{tmax}-0)(P / B)}
$$

Dividing equation (A.1.4) by equation (A.1.2) results in

$$
\frac{N_{\operatorname{tmax}}}{N_{1}}=e^{(1-0)\left(\frac{P}{B}\right)_{Y}-(\operatorname{tmax}-0)\left(\frac{P}{B}\right)} .
$$

From equations (A.1.3) and (A.1.5), we can estimate $(P / B)_{A}$, the total mortality for adults, as

$$
(P / B)_{A}=\left\{\left(\frac{P}{B}\right)_{Y}-\operatorname{tmax}\left(\frac{P}{B}\right)\right\} /(1-\operatorname{tmax}) .
$$

We use Silver Carp to illustrate how we calculated $(P / B)_{Y}$ for young-of-year $\mathrm{AC}$ and $(P / B)_{A}$ for age-1+ fish: $(P / B)_{Y}$ for young-of-year Silver Carp includes two mortality terms, predation mortality and other mortality (natural mortality excluding predation mortality). Predation mortality was calculated based on predators' consumption (the product of the AC fractions in predators' diets, predator biomass, and predators' consumption-biomass ratio in Ecopath) and the biomass of young-of-year Silver Carp. Other mortality was assumed to be 1.6 (Naseka and Bogutskaya 2011). The total consumption of young-of-year Silver Carp by predators was $1.14 \mathrm{~kg} / \mathrm{ha} /$ year $^{-}$. As the initial biomass of young-of-year Silver Carp was $0.4 \mathrm{~kg} / \mathrm{ha}$, predation mortality was $2.85 /$ year. Therefore, $(P /$ $B)_{Y}=(1.6+2.85) /$ year $=4.45 /$ year. Since the maximum lifespan for Silver Carp is 15 years and the $P / B$ value for Silver Carp selected from structured expert judgment is 1.08, equation (A.1.6) gives us $(P / B)_{A}=(4.45-15[1.08]) /$ $(1-15)=0.839 /$ year.

\section{APPENDIX A.1 REFERENCES}

Naseka, A., and N. Bogutskaya. 2011. Annotated bibliography of Bighead (Hypophthalmichthys nobilis) and Silver (Hypophthalmichthys molitrix) carps from Russian-language literature. Canadian Manuscript Report of Fisheries and Aquatic Sciences 2964.

\section{Appendix A.2: Additional Tables}

TABLE A.2.1. Diet composition (percent by volume) of Asian carps from Chen (1982); the ratio of volume to biomass was assumed to be 1:1.

\begin{tabular}{lccc}
\hline Prey & In lake water & Silver Carp & Bighead Carp \\
\hline Detritus & 36.65 & 39.07 & 26.58 \\
Bacteria & 28.14 & 26.12 & 17.0 \\
Phytoplankton & 17.00 & 22.61 & 14.03 \\
Zooplankton & 18.21 & 12.20 & 42.39 \\
\hline
\end{tabular}


TABLE A.2.2. Mean \pm SD parameter values in balanced Ecopath models for Asian carps (AC) under different scenarios. Scenarios are as follows: high detritus in the $\mathrm{AC}$ diet (AC_HD), low detritus in the $\mathrm{AC} \operatorname{diet}\left(\mathrm{AC} \_\mathrm{LD}\right)$, no detritus in the $\mathrm{AC}$ diet (AC_ND), larval fish in the AC diet (AC_LF), and high phosphorus loads (AC_HP). See Table 1 for an explanation of the codes for the species groups.

\begin{tabular}{|c|c|c|c|c|c|}
\hline Species/group & AC_HD & AC_LD & AC_ND & AC_LF & AC_HP \\
\hline \multicolumn{6}{|c|}{ Number of balanced Ecopath models } \\
\hline & 86 & 88 & 85 & 81 & 88 \\
\hline \multicolumn{6}{|c|}{$P / B$ for whole population } \\
\hline Bighead Carp & $1.8 \pm 0.9$ & $1.7 \pm 1$ & $1.8 \pm 1$ & $1.8 \pm 1$ & $1.6 \pm 0.9$ \\
\hline Silver Carp & $1.6 \pm 0.9$ & $1.7 \pm 0.9$ & $1.9 \pm 1.1$ & $1.9 \pm 1.1$ & $1.7 \pm 1$ \\
\hline \multicolumn{6}{|c|}{$Q / B$ for age-1+ AC } \\
\hline Bighead Carp & $19.8 \pm 15$ & $20 \pm 14.4$ & $17.4 \pm 12.2$ & $16.2 \pm 9.3$ & $20.2 \pm 16.8$ \\
\hline Silver Carp & $18 \pm 11.5$ & $19.6 \pm 17.7$ & $19.3 \pm 16.3$ & $22.2 \pm 21.2$ & $17.8 \pm 6.7$ \\
\hline \multicolumn{6}{|c|}{ Total diet fraction of Asian carps ${ }^{\mathrm{a}}$} \\
\hline DCCM & $4.7 \pm 2.4$ & $4.9 \pm 2.6$ & $5.3 \pm 2.8$ & $4.4 \pm 2.5$ & $5.2 \pm 2.6$ \\
\hline MERG & $5.3 \pm 2.9$ & $5.6 \pm 2.7$ & $4.7 \pm 2.8$ & $5.2 \pm 2.6$ & $5 \pm 2.6$ \\
\hline WAE_Y & $1 \pm 0.7$ & $1 \pm 1.2$ & $1.3 \pm 1.2$ & $0.9 \pm 0.6$ & $1.1 \pm 1.2$ \\
\hline WAE_J & $5.1 \pm 2.7$ & $5.4 \pm 2.7$ & $5.6 \pm 2.6$ & $5.6 \pm 2.8$ & $5.4 \pm 2.5$ \\
\hline WAE_A & $2.9 \pm 1.4$ & $3.3 \pm 1.5$ & $3 \pm 1.3$ & $3.1 \pm 1.8$ & $3 \pm 1.4$ \\
\hline YEP_Y & $0 \pm 0.3$ & $0 \pm 0.3$ & $0.1 \pm 0.4$ & $0.1 \pm 0.4$ & $0.1 \pm 0.3$ \\
\hline YEP_J & $2.7 \pm 1.6$ & $2.7 \pm 1.7$ & $2.3 \pm 1.4$ & $2.6 \pm 1.5$ & $2.7 \pm 1.5$ \\
\hline YEP_A & $1.9 \pm 1$ & $1.8 \pm 1.1$ & $2 \pm 0.9$ & $2 \pm 1$ & $2 \pm 1.1$ \\
\hline GIZ & $0 \pm 0$ & $0 \pm 0.2$ & $0 \pm 0.1$ & $0.1 \pm 0.8$ & $0 \pm 0.3$ \\
\hline RBT_A & $0.9 \pm 1.1$ & $0.9 \pm 1.4$ & $0.9 \pm 1.1$ & $0.9 \pm 1.3$ & $1 \pm 1$ \\
\hline LWF & $0.2 \pm 0.8$ & $0.1 \pm 0.5$ & $0.2 \pm 0.7$ & $0.2 \pm 0.7$ & $0.1 \pm 0.6$ \\
\hline BBT & $0.5 \pm 0.6$ & $0.3 \pm 0.3$ & $0.4 \pm 0.5$ & $0.5 \pm 0.6$ & $0.5 \pm 0.5$ \\
\hline WHB & $1.6 \pm 1.7$ & $1.2 \pm 1.2$ & $1.2 \pm 1.1$ & $1.4 \pm 1.4$ & $1.3 \pm 1.3$ \\
\hline WHP & $1.3 \pm 1.3$ & $1 \pm 0.5$ & $1.1 \pm 0.5$ & $1.3 \pm 1.3$ & $1.2 \pm 0.8$ \\
\hline SMB & $3.2 \pm 1.7$ & $3.2 \pm 1.7$ & $3 \pm 1.6$ & $3.1 \pm 1.3$ & $3 \pm 1.4$ \\
\hline FWD & $0.4 \pm 0.8$ & $0.7 \pm 1.6$ & $0.4 \pm 0.9$ & $0.3 \pm 1$ & $0.3 \pm 0.5$ \\
\hline ALW & $0 \pm 0.4$ & $0.1 \pm 0.6$ & $0.2 \pm 0.9$ & $0.1 \pm 0.7$ & $0.1 \pm 0.7$ \\
\hline LKT_A & $0.1 \pm 0.2$ & $0.2 \pm 0.3$ & $0.1 \pm 0.3$ & $0.2 \pm 0.3$ & $0.2 \pm 0.3$ \\
\hline $\mathrm{RBS}^{-}$ & $0.2 \pm 0.8$ & $0.2 \pm 0.8$ & $0.2 \pm 0.8$ & $0.1 \pm 0.4$ & $0 \pm 0.1$ \\
\hline CMP & $0 \pm 0.3$ & $0.1 \pm 0.4$ & $0.1 \pm 0.3$ & $0.1 \pm 0.4$ & $0.1 \pm 0.3$ \\
\hline RGB & $0.1 \pm 0.4$ & $0 \pm 0$ & $0.1 \pm 0.3$ & $0.1 \pm 0.4$ & $0.1 \pm 0.3$ \\
\hline SUK & $0.1 \pm 0.3$ & $0.1 \pm 0.3$ & $0 \pm 0$ & $0.2 \pm 0.7$ & $0.1 \pm 0.5$ \\
\hline EMS & $0.1 \pm 0.3$ & $0.1 \pm 0.5$ & $0 \pm 0.1$ & $0.1 \pm 0.6$ & $0.2 \pm 0.7$ \\
\hline CAT & $1.1 \pm 0.8$ & $1 \pm 0.9$ & $0.9 \pm 0.7$ & $1 \pm 0.8$ & $0.9 \pm 0.7$ \\
\hline PanF & $0 \pm 0$ & $0.1 \pm 0.7$ & $0.2 \pm 0.9$ & $0.1 \pm 0.6$ & $0.2 \pm 0.8$ \\
\hline \multicolumn{6}{|c|}{ Resulting predation mortality and ecotrophic efficiency of young-of-year $\mathrm{AC}^{\mathrm{b}}$} \\
\hline Predation mortality & $4.1 \pm 1.9$ & $4.1 \pm 2.3$ & $3.8 \pm 1.8$ & $4.9 \pm 4.5$ & $4.0 \pm 2.4$ \\
\hline Ecotrophic efficiency & $0.70 \pm 0.07$ & $0.69 \pm 0.08$ & $0.68 \pm 0.07$ & $0.71 \pm 0.08$ & $0.69 \pm 0.07$ \\
\hline
\end{tabular}

${ }^{\mathrm{a} S c a l e d}$ down by 10 ; see text for details.

${ }^{\mathrm{b}} \mathrm{S}$ ame for young Bighead and Silver carp. 
TABLE A.2.3. Asian carp biomass (mean; $\mathrm{kg} / \mathrm{ha}$ ) during the final 10 years of the simulations, along with the number of Ecopath models not reaching mass balance and the causes of unbalance: high predation mortality on young AC (H_pred); zero consumption $(Q / B=0)$; negative AC respiration (N_resp); EEs of cladocerans, copepods, or predatory cladocerans greater than 1 (ZP_EE $>1$ ); and high predation mortality by AC on larval walleyes (Larvae). SCP_Y $=$ young Silver Carp, SCP_A = age 1+ Silver Carp; BCP_Y = young Bighead Carp, and BCP_A = age 1+ Bighead Carp. Standard deviations of mean biomass are in parentheses.

\begin{tabular}{|c|c|c|c|c|c|}
\hline Variable & AC_HD & AC_LD & AC_ND & AC_LF & AC_HP \\
\hline \multicolumn{6}{|c|}{ Number of Ecopath models not achieving mass balance } \\
\hline & 14 & 12 & 15 & 19 & 12 \\
\hline \multicolumn{6}{|c|}{ Causes of unbalance } \\
\hline H_pred & 7 & 7 & 9 & 6 & 9 \\
\hline$Q / B=0$ & 1 & 2 & 2 & 2 & 3 \\
\hline N_resp & 2 & 1 & 3 & 5 & 0 \\
\hline ZP_EE > 1 & 4 & 2 & 1 & 0 & 0 \\
\hline Larvae & & & & 6 & \\
\hline \multicolumn{6}{|c|}{ AC biomass (kg/ha) } \\
\hline SCP_Y & $1.58(0.19)$ & $1.57(0.23)$ & $1.60(0.18)$ & $1.66(0.23)$ & $2.28(0.31)$ \\
\hline SCP_A & $32.21(31.63)$ & $32.29(34.01)$ & $27.43(26.40)$ & $29.25(40.30)$ & $51.46(64.98)$ \\
\hline BCP_Y & $1.48(0.18)$ & $1.41(0.21)$ & $1.38(0.18)$ & $1.51(0.22)$ & $2.43(0.27)$ \\
\hline BCP_A & $22.94(24.87)$ & $25.23(24.59)$ & $21.95(23.03)$ & $23.70(22.17)$ & $48.16(42.27)$ \\
\hline \multicolumn{6}{|c|}{ TotalAC biomass (kg/ha) } \\
\hline Mean & $58.21(44.72)$ & $60.50(46.24)$ & $52.36(33.62)$ & $56.12(48.87)$ & $104.3(74.93)$ \\
\hline Median & 50.81 & 57.88 & 54.50 & 47.75 & 99.80 \\
\hline Maximum & 245.80 & 203.85 & 150.80 & 323.42 & 394.23 \\
\hline Minimum & 2.37 & 2.16 & 2.37 & 2.45 & 5.02 \\
\hline \multicolumn{6}{|c|}{ Mean \% AC biomass in total fish biomass } \\
\hline & $30.3(16.9)$ & $31.0(18.3)$ & $29.3(15.0)$ & $29.0(17.4)$ & $33.9(16.9)$ \\
\hline \multicolumn{6}{|c|}{ Number of Ecosim models with AC biomass $>200 \mathrm{~kg} / \mathrm{ha}$} \\
\hline & 1 & 1 & 0 & 1 & 7 \\
\hline
\end{tabular}

TABLE A.2.4. Comparisons of total phosphorus, chlorophyll $a$ concentration, and selected zooplankton taxa biomass estimates $\left(\mathrm{mg}\right.$ wet weight $\left./ \mathrm{m}^{3}\right)$ between Lake Erie and the Illinois River.

\begin{tabular}{lll}
\hline Variable & Lake Erie & Illinois River \\
\hline Total phosphorus $(\mathrm{mg} / \mathrm{L})$ & $0.019(0.007)^{\mathrm{a}}$ & $0.36(0.11)^{\mathrm{c}}$ \\
Chlorophyll $a(\mu \mathrm{g} / \mathrm{L})$ & $2.6(1.2)^{\mathrm{a}}$ & $27.2(17.5)^{\mathrm{c}}$ \\
Cladocerans & $4.39^{\mathrm{b}}$ & $1.56^{\mathrm{d}}$ \\
Copepods & $3.49^{\mathrm{b}}$ & $2.11^{\mathrm{d}}$ \\
\hline
\end{tabular}

${ }^{\mathrm{a}}$ Charlton et al. (2010)

${ }^{\mathrm{b}}$ Munawar et al. (2008).

${ }^{\mathrm{c}}$ Johnson and Hagerty (2008).

${ }^{\mathrm{d}}$ Estimated from Sass et al. (2014) assuming an average depth of $4 \mathrm{~m}$ and a dry weight : wet weight ratio of $10 \%$. 


\section{APPENDIX A.2 REFERENCES}

Charlton, M., J. Vincent, C. Marvin, and J. Ciborowski. 2010. Status of nutrients in the Lake Erie basin. Prepared by the Lake Erie Nutrient Science Task Group for the Lake Erie Lakewide Managment Plan, Windsor, Ontario.

Chen, S. 1982. [Studies on the Feeding spectrum of Silver Carp and Bighead Carp fingerlings in Lake Donghu (China).] Reservoir Fisheries of China 3:21-26. (In Chinese).

Johnson, B. L., and K. H. Hagerty. 2008. Status and trends of selected resources of the upper Mississippi River system. U.S. Geological Survey, Technical Report LTRMP 2008-T002, La Crosse, Wisconsin.
Munawar, M., I. F. Munawar, M. Fitzpatrick, H. Niblock, K. Bowen, and J. Lorimer. 2008. An intensive assessment of planktonic communities in the Canadian waters of Lake Erie, 1998. Pages 297-346 in M. Munawar and R. Heath, editors. Checking the pulse of Lake Erie. Aquatic Ecosystem Health and Management Society, Burlington, Ontario.

Sass, G. G., C. Hinz, A. C. Erickson, N. N. McClelland, M. A. McClelland, and J. M. Epifanio. 2014. Invasive Bighead and Silver carp effects on zooplankton communities in the Illinois River, Illinois, USA. Journal of Great Lakes Research 40:911-921.

\section{Appendix A.3: Additional Figures}

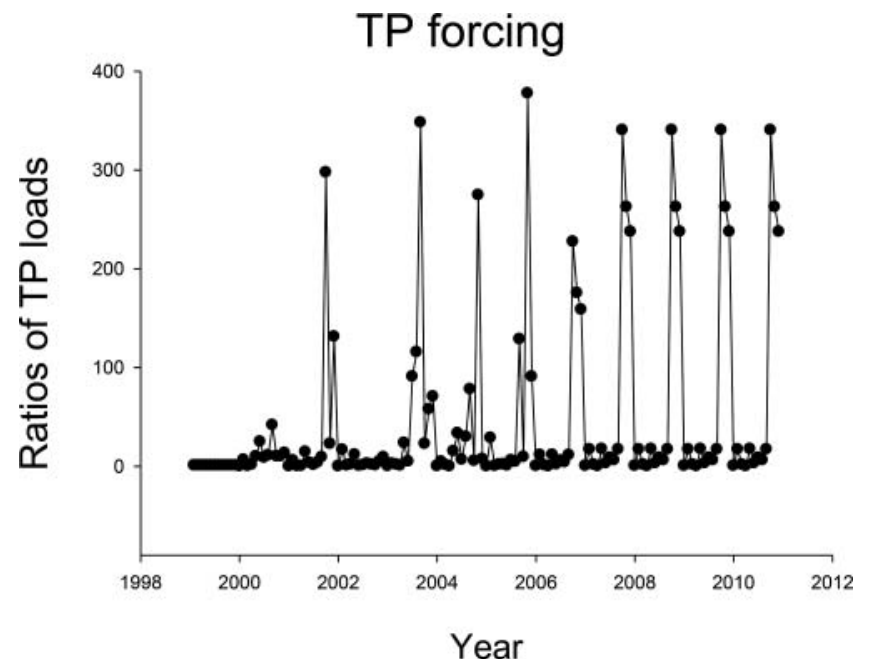

FIGURE A.3.1. Nutrient loading forcing function (ratios of the total phosphorus [TP] load in a given month to that in the same month in 1999) used in Ecosim simulations for Lake Erie. The annual TP loads are from David Dolan (University of Wisconsin-Green Bay).

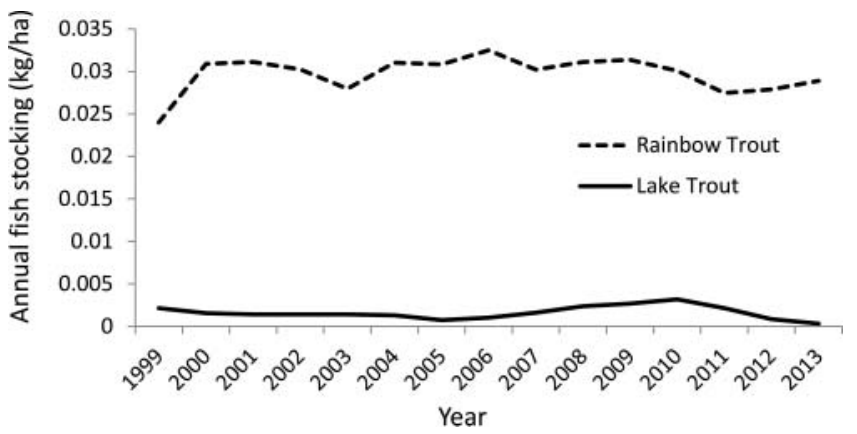

FIGURE A.3.2. Annual fish stocking biomass for Rainbow Trout and Lake Trout. The valuesare based on those in the 2014 annual report by the Lake Erie Cold Water Task Group (http://www.glfc.org/lakecom/lec/CWTG_docs/ annual_reports/CWTG_report_2014.pdf [March 2015]). 


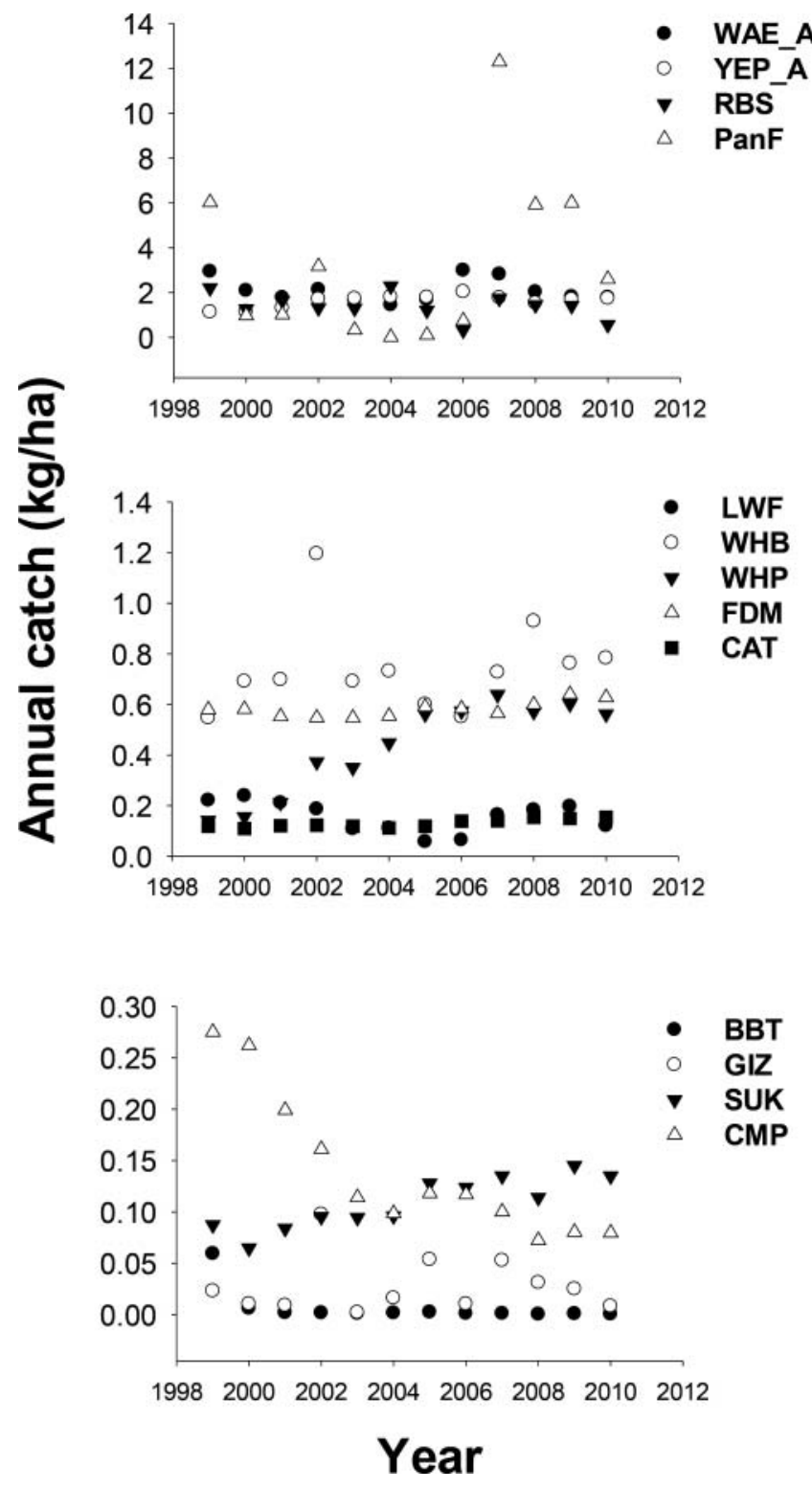

FIGURE A.3.3. Annual fishery catches in Lake Erie, 1999-2010, for selected species (see Table 1 in the text for species codes).

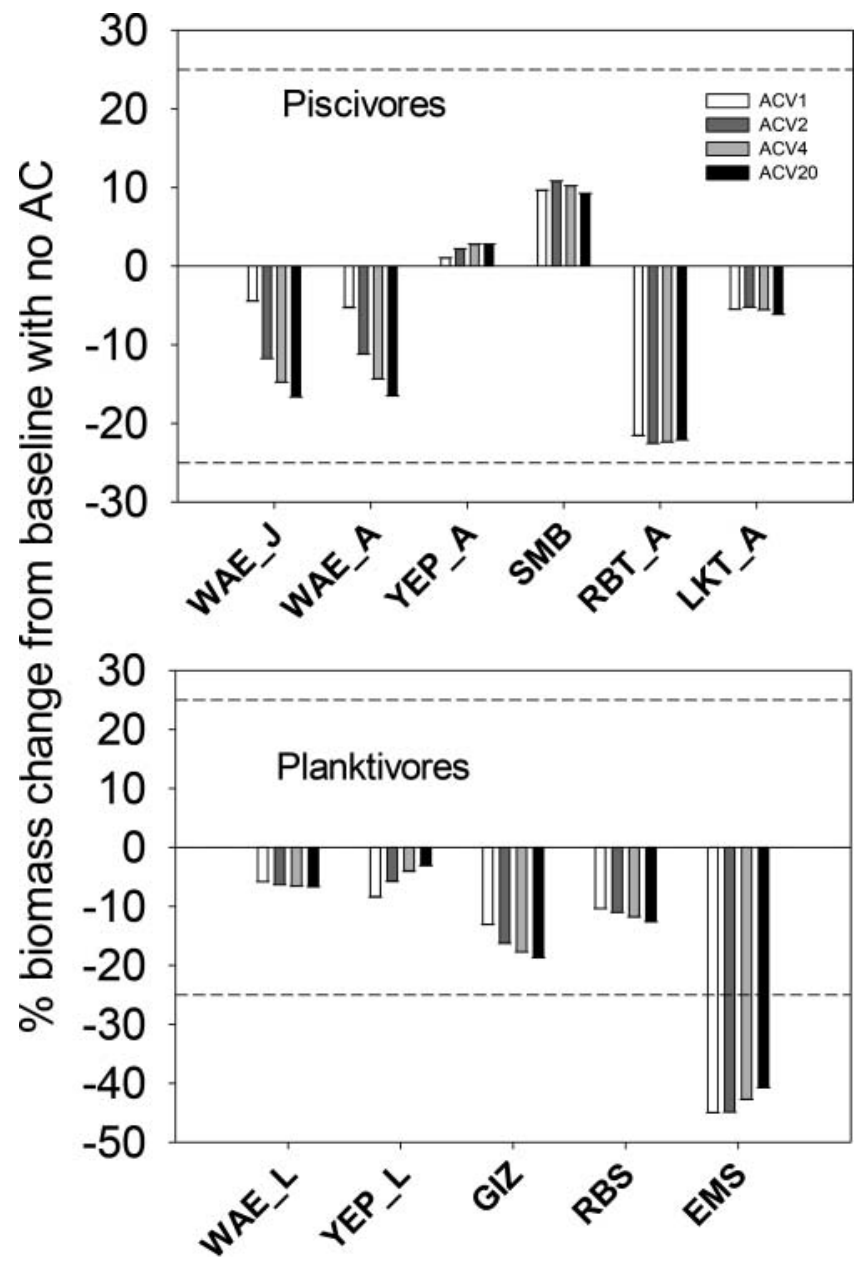

FIGURE A.3.4. Percent change in biomass of piscivorous and planktivorous fishes from the baseline condition of no $\mathrm{AC}$ assuming different vulnerabilities of young $\mathrm{AC}$ to predators $(\mathrm{ACV}=1,2,4,20$ with the vulnerability of prey to $\mathrm{AC}=11$. The dashed lines represent $25 \%$ declines from the baseline condition. 